\title{
$\begin{array}{llllllll}\mathrm{A} & \mathrm{R} & \mathrm{T} & \mathrm{I} & \mathrm{C} & \mathrm{L} & \mathrm{E} & \mathrm{S}\end{array}$
}

\section{PIPELINES AND THEIR PORTFOLIOS: A MORE HOLISTIC VIEW OF HUMAN CAPITAL HETEROGENEITY VIA FIRM-WIDE EMPLOYEE SOURCING}

\author{
RHETT A. BRYMER * \\ University of Cincinnati \\ CLINT CHADWICK \\ University of Kansas \\ AARON D. HILL \\ University of Florida \\ JANICE C. MOLLOY \\ University of Michigan at Dearborn
}

\begin{abstract}
Scholars use the term pipelines to encapsulate many ways that firms target talent sources. Yet pipeline scholarship is fragmented to date, so we have few answers for several salient questions: Why do pipelines exist? What are their attributes? And what are their implications for firms? In this paper, we explore these questions. Based on an extensive literature review, we first distill the commonalities and core attributes of pipelines and then develop a theory-driven typology to ensure a consistency in understanding. Next, we suggest that a common theoretical justification runs through the uses of pipelines: Pipelines address labor market imperfections confronted by firms when they staff positions, counterbalancing the seemingly detrimental reduction in candidates that pipelines engender. We use this insight to theoretically delineate why different types of pipelines exist. Finally, we discuss how firms develop unique combinations, or portfolios, of pipelines to ameliorate the range of imperfections that they face to manage talent sourcing across the enterprise. In total, our paper describes how firms strategically manage pipeline portfolios, why firms turn to them to accumulate talent, and how they create between-firm heterogeneity of human capital resources.
\end{abstract}

The second and third authors contributed equally to this work. We are grateful to Peter Cappelli, Lisa Ellram, Megan Gerhardt, John Mawdsley, Seamus DaFino, Mike Hitt, Action Editor Geoffrey Wood, two anonymous reviewers, and participants at Wharton's 2014 People \& Organizations Conference, Ohio State University's 2015 Research Series, the University of Memphis's 2016 Research Series, and the Strategic Management Society's 2017 Special Conference for Strategic Human Capital for suggestions on previous versions of this work. We are also indebted to David Lepak for his comments on this work, his inspiration, and his contributions to our field. He left us much too soon.

${ }^{*}$ Corresponding author.
How firms create human capital differentiation is a central question of management scholarship because it can be a vital source of competitive advantage (Barney \& Wright, 1998; Chadwick, 2017). In particular, scholars have made significant advances in the area of staffing, noting best practices for selection, onboarding, and development of human capital value and, subsequently, firm performance (e.g., Ployhart, 2006). Despite the wealth of scholarship in this vein, however, one underdeveloped area of scholarship persists: how and why firms target particular sources of human capital. Indeed, Ployhart, Schneider, and Schmitt (2006, p. 291) described targeting of particular human capital sources as 
imperative but with "essentially no research," while Breaugh (2008, p. 111) lamented that a topic that is so fundamental to talent strategy has "received so little attention." More recently, Phillips and Gully (2015) and Ployhart and Cragun (2017) echoed these sentiments, noting the explanatory power that targeted sourcing could have on human capital differentiation between firms, yet pointing out that topical research is embryonic.

As we will describe, scholars have begun wrestling with the idea of sourcing talent in more targeted ways, though the research is quite fragmented and has principally attracted another label: pipelines. Aside from the rare conditions when employee sourcing approximates an unfettered spot market for labor, much of firms' activity in this realm involves managing a sequenced flow of repeated staffing from targeted human capital sources to firms, occupations, and geographies through what scholars in a variety of disciplines have described as pipelines (Brands \& Fernandez-Mateo, 2017; Brymer, Molloy, \& Gilbert, 2014, Cappelli, 2008a, 2008b; Conger \& Fulmer, 2003; Fernandez-Mateo \& Fernandez, 2016; Helfat, Harris, \& Wolfson 2006; Rocha, Carneiro, \& Varum, 2018; Stewart, Williamson, \& King, 2008; Ulrich \& Smallwood, 2007). ${ }^{1}$ Scholars use the pipeline term to encapsulate many ways that firms target talent sources to improve the likelihood of getting the right person in the right job at the right time. Yet because pipeline scholarship is so fragmented, we have few answers to salient questions: Why do pipelines exist? What are their attributes? And what are the implications for firms that use pipelines? In this paper, we explore these questions.

The fragmentation of pipeline scholarship can be attributed in part to what McKinley (2007) called deobjectification, whereby scholars use a single term (pipelines) to refer to related but objectively different entities. The de-objectification of pipelines impedes our ability to aggregate knowledge on targeted talent sourcing. Without clear definitions and consistent terminology, we lack precision in our knowledge and may even confound understanding when distinct pipelines affect the same outcome differently or have different underlying mechanisms that are inconsistent (cf. Oxley et al., 2010; Suddaby, 2010). Establishing a typology with clear terminology is

\footnotetext{
${ }^{1}$ The term pipelines is often used in combination with descriptive adjectives such as employee, talent, hiring, human capital, and leadership. For parsimony, we use the term pipelines in reference to all types of repeated, quasimarket staffing practices firms use (see Brymer et al., 2014).
}

imperative to build shared knowledge in this growing literature stream.

Based on an extensive literature review, in this paper we distill the commonalities and core attributes of pipelines and develop a theory-driven typology to ensure both a consistency in understanding and a platform from which future knowledge of pipelines can be created. One common characteristic of pipelines is that they reduce the number of workers a firm considers (rather than considering all applicants in the broad market). Pipelines constrain and restrict the supply of talent, which is seemingly counterproductive to firm interests of identifying the best candidates. We suggest that a common theoretical justification runs through the uses of all pipelines that counterbalances the reduction in potential applicants: Pipelines address labor market imperfections that firms confront in staffing positions (see Campbell, Coff, \& Kryscynski, 2012; Chadwick, 2017; Mahoney \& Qian, 2013). We use this insight to theoretically delineate why different types of pipelines exist.

Moreover, firms continuously staff across various positions and geographies, and each labor market typically presents an idiosyncratic assortment of imperfections. Consequently, firms develop unique combinations, or portfolios, of pipelines to ameliorate the multiple imperfections they face and manage sourcing across the enterprise. This paper describes how and why pipelines create between-firm heterogeneity, how firms choose between pipelines, and why firms are increasingly turning to portfolios of pipelines to manage their enterprise-wide talent accumulation. We contend that this concept of firmspecific pipeline portfolios has profound implications for deepening our explanations about how firms accumulate talent over time. From a more holistic sourcing perspective, organizational capabilities to configure effective portfolios of pipelines are fundamental to the creation of differentiated human capital resources among firms (Chadwick, 2017; Ployhart, Nyberg, Reilly, \& Maltarich, 2014). We turn first to the conceptualization of pipelines that exists in research to date to establish a common foundation for our discussion.

\section{STAFFING AND TARGETED SOURCING}

In today's labor markets, firms have a wide array of staffing options. In some cases, managers hire from the general labor market, using job boards such as Indeed and Monster to appeal to a broad pool of potential candidates (Ryan \& Ployhart, 2014). In other 
cases, managers take a targeted approach, choosing to hire only from particular labor sources ${ }^{2}$ to avoid the potential costs (e.g., time, asymmetric information about potential employees) associated with sourcing from such a broad pool. Examples of such sources include internal rotational programs and specific labor market intermediaries (Bonet, Cappelli, \& Hamori, 2013; Osterman \& Burton, 2006).

Differences in both labor sources and the effectiveness with which firms leverage them can lead to variation among firms in the makeup of their applicant and candidate pools. Once staffing from targeted sources is established and firms return repeatedly to these same sources to hire, the flow of hired workers from those sources becomes what scholars have referred to as a pipeline (Cappelli, 2008a, 2008b; Conger \& Fulmer, 2003; FernandezMateo \& Fernandez, 2016; Helfat et al., 2006; Stewart et al., 2008; Ulrich \& Smallwood, 2007). Pipeline sourcing can beget firm heterogeneity in human capital resources and in firm performance (Brymer et al., 2014).

Unlike other talent acquisition and development scholarship that has more established formal definitions of key constructs, the pipelines term has been used in a largely fragmented, informal, and disconnected manner across a variety of disciplines. Despite this fragmentation of the concept, it has nonetheless emerged to denote repeated staffing from sources as a conceptually intuitive idea with a growing body of inquiry. Nevertheless, the current mutability of this concept has hindered us from forming a broader theoretical understanding. Given this shortcoming, we turn to the current literature to review the working uses of the term from which to build a more coherent, theoretically driven concept that can be applied more rigorously and holistically.

\section{THE PIPELINE CONCEPT}

We build our conceptualization on prior work that surfaced in our systematic review of scholarship

\footnotetext{
${ }^{2}$ Labor sources comprise pools of individuals in the larger labor market who share a common affiliation and/or a specific set of attributes. In the context of this paper, we examine repeated staffing from these sources over time. Examples of labor sources include employees at a preferred vendor organization, students at a partner university program, focal firm "graduates" of a leadership development program, women with a specialized skill set, and future dentists who want to practice in underserved communities.
}

pertaining to pipelines and employment. We conducted the review using best practices (e.g., multiple coders, clear inclusion criteria, broad sampling frame; Miles \& Huberman, 1994). For a thorough explanation of the review process and details of the findings, please see the appendix. After reading each article, we determined that pipelines were a key concept in 107 academic articles. What follows is a distillation of this extensive review for the purposes of creating a common understanding of pipelines' core attributes.

\section{Pipeline Definition}

With one exception (Brymer et al., 2014), the articles we reviewed do not explicitly define pipelines. Most articles discuss the pipeline concept with the implicit understanding that the reader will understand the reference to the systematic flow of employees described, be they talented workers, leaders, or any number of other forms of worker traits in firms' current and potential labor pool. None of these existing implicit and explicit definitions individually encompasses the range of pipeline phenomena that surfaced in our review. For example, Brymer and colleagues' (2014) definition focuses on external hiring but does not address pipeline phenomena that exist in internal labor markets, such as firms' efforts to develop leadership skills (e.g., Bersin, 2012; Conger \& Fulmer, 2003), or pipelines that build the supply of future workers for particular occupations or underserved locations, such as women in engineering occupations and doctors in rural communities (e.g., Atchison et al., 2011; Carson, Schoo, \& Berggren, 2015). Through their descriptions, other studies implicitly define pipelines narrowly in different ways, such as individuals progressing through an executive search firm and its processes (Brands \& Fernandez-Mateo, 2017) or internal labor market paths to top management positions (Ulrich \& Smallwood, 2007).

We build a common definition based on that of Brymer and colleagues (2014, p. 488), who described a pipeline as "repeated disproportionately high [levels of hiring] relative to the general labor market" by one firm from one specific external source organization. Based on the breadth of our findings from the other 106 articles in our review, we broaden the definition of pipelines to be the sequenced flow and development of individuals repeated over time, disproportionately from specific labor sources into particular positions within firms, occupations, and geographies. This definition reflects several salient 
features: repeated and sequenced hiring patterns, "leakage" (i.e., when workers exit the pipeline; Brands \& Fernandez-Mateo, 2017; Pell, 1996), movement and development of workers, and market thickening of a specific labor supply. We proceed by summarizing these fundamental features.

\section{Repeated, Sequenced Movement With Leakage}

Repeatedly staffing from the same source is an essential characteristic that differentiates pipelines from more general hiring practices. Although returning to the same source does not preclude a firm from also searching the broader labor market, a firm may choose to leverage the benefits that pipelines offer while avoiding the costs of using the general market (e.g., search costs, idiosyncratic information of any single application). In so doing, a firm intentionally narrows its pools of applicants, which may seem counterproductive to effective staffing. Although it is certainly possible that some firms make this choice arbitrarily, pipelines offer a number of potential benefits.

One benefit is the sequenced pattern that a pipeline entails, which queues individuals through preidentified steps from a labor source into particular positions in firms or professions. This patterned movement not only benefits individuals in the pipeline, allowing them privileged access to opportunities and job openings not available to the larger labor market, but it also benefits firms by offering them ex ante information about potential workers in the pipeline that can result in better selection. Firms can use knowledge obtained in the sequenced pipeline steps to ascertain whether individuals fit with the organization, job, and coworkers (Kristof-Brown, Zimmerman, \& Johnson, 2005). Thus, pipeline sequencing helps address labor market information asymmetries.

The sequential nature of a pipeline guides individuals from one developmental stage (e.g., undergraduate student in a specific university) to another (e.g., graduate student in a specific program) and ultimately into a particular hiring firm. Consequently, individuals not in the favored undergraduate university or the graduate program will find it more difficult to gain access to the hiring firm. At the same time, those who do not perform at certain levels in the undergraduate program may not receive the opportunity to advance to the graduate program. In other words, these patterns tend to be exclusionary and may incorporate many organizations into particular pipelines, ultimately sorting the potential workers across several steps, funneling individuals through those steps, and yielding inequalities in employment outcomes (e.g., Bidwell, 2013; Bidwell, Briscoe, Fernandez-Mateo, \& Sterling, 2013; Cobb, 2016). Yet the sorting also provides the hiring firms with more assurances that those who have gone through the sequence have specific shared characteristics, reducing search costs and mitigating information asymmetries associated with hiring individuals from the broader market. Thus, pipelines can function as an assortative matching mechanism between individuals and firms.

In the process of funneling specific groups of workers to positions, pipelines inevitably involve both intended and unintended leakage-that is, individuals who do not advance to the next step in the sequence. A wealth of research on diversity and professional skill deficits has adopted this sequential perspective and examined when and why individuals exit (i.e., leak from) the pipeline (e.g., Acosta \& Olsen, 2006; Brands \& Fernandez-Mateo, 2017; Carson et al., 2015; Fernandez-Mateo \& Fernandez, 2016; Helfat et al., 2006; Karpinski, 2006). Independent of exclusionary practices that restrict the individual workers' consideration for a position outside of merit (e.g., gender and ethnic bias), resulting in unintentional leakage, leakage that is intentional eliminates individuals who lack the requisite characteristics from the pipeline.

\section{Movement, Development, and Market Thickening}

Like physical pipelines that deliver substances such as oil from a large deposit to other locations, talent pipeline descriptions imply flow and movement. Unlike broader staffing approaches, pipelines have long temporal scopes as they involve steady matching between particular pools of employees and firms that wish to employ them. Such repeated hiring etches patterns of mobility into the focal labor market.

In contrast to physical pipelines, which are generally limited to movement of fluids, pipelines can also facilitate development of potential employees over time. Consider the quotes in Table 1 that describe pipelines as a set of discrete developmental steps that workers take to advance from the source (or sources) to the firm, occupation, and/or geography. Each step along a pipeline thus facilitates better matches between workers and organizations in two related ways: first by decreasing information asymmetries, and second by developing potential workers' human capital to better fit firms' requirements. The 
TABLE 1

Illustrative Quotes for General Pipeline Attributes

\begin{tabular}{|c|c|}
\hline Features & Examples \\
\hline Repeated, sequenced movement with leakage & $\begin{array}{l}\text { We conducted a survey of human resources executives from } 40 \text { companies around } \\
\text { the world in 2005, and virtually all of them indicated that they had an insufficient } \\
\text { pipeline of high-potential employees to fill strategic management roles. (Ready \& } \\
\text { Conger, 2007, p. 68) } \\
\text { The findings provide evidence that [school] principals are capable of effectively } \\
\text { identifying and encouraging teachers with strong leadership potential to enter the } \\
\text { principal pipeline, although additional training and a succession management } \\
\text { plan may help ensure that teachers are selected based on clear leadership } \\
\text { competencies. (Myung, Loeb, \& Horng, 2011, p. 696) } \\
\text { As companies continue to see their pipelines leak at mid-to-senior levels even though } \\
\text { they've invested considerable time and resources in mentors and developmental } \\
\text { opportunities, they are actively searching for ways to retain their best female talent. } \\
\text { (Ibarra, Carter, \& Silva, 2010, p. 82) }\end{array}$ \\
\hline Movement, development, and market thickening & $\begin{array}{l}\text { These discussions often center around a "pipeline metaphor" that imagines students } \\
\text { flowing through a series of experiences to eventually arrive at a science career. } \\
\text { (McGee, Saran, \& Krulwich, 2012, p. 397) } \\
\text { [T]he issues in managing an internal talent pipeline-the ways employees advance } \\
\text { through development jobs and experiences-are remarkably similar to those } \\
\text { involved in moving products through a supply chain. (Cappelli, 2008b, p. 6) } \\
\text { A lack of strategic workforce planning and development of a leadership pipeline } \\
\text { contributes to a predicted nurse manager shortage. (Titzer, Shirey, \& Hauck, 2014, } \\
\text { p. 37) } \\
\text { One might suppose that a rich pipeline of qualified individuals would ultimately } \\
\text { result in women rising to the top over time, thus breaking the glass ceiling naturally } \\
\text { and without requiring specific policies to end gender discrimination. (Monroe \& } \\
\text { Chiu, 2010, p. 305) }\end{array}$ \\
\hline
\end{tabular}

developmental aspects of pipelines help explain not only why intended leakage may be desirable, but also why firms would consider excluding some possible applicants: Pipelines allow firms to help develop potential workers into better hires as well as to select them more effectively.

The ultimate output of workers through pipelines typically results in scarce human capital resources that are highly valued, in limited supply, and vital to an organization's functioning. Thus pipelines can be an important, labor market-based complement to current theoretical explanations for cross-firm variance in human capital resources that focus on internal, firm-specific processes that generate human capital complementarities (cf. Ployhart et al., 2014). For example, scholars describe nurses (Maxwell, 2004; Titzer, Shirey, \& Hauck, 2014), female executives (Brands \& Fernandez-Mateo, 2017), individuals holding business Ph.D.s who are members of ethnic minority groups (Stewart et al., 2008), and workers with specialized skills (Brymer et al., 2014; Connolly \& Phillips-Connolly, 2010) as people who move through pipelines. Firms that are able to gain favorable access to these valuable, and in limited supply, resources can secure competitive advantages, and pipelines offer one means to do so (Brymer et al., 2014). Importantly, the scarce human capital in question is not always the individual's knowledge or skills. Rather, the scarce human capital can be an interest, such as a desire to work in underserved areas, as evidenced by scholarship on teachers interested in working in urban areas (Clewell \& Villegas, 1999) and dentists interested in working in rural areas (Alexander \& Mitchell, 2010; Formicola et al., 2009). Other times the scarcity is reflected in a demographic, such as female biologists (Dutta-Moscato, Gopalakrishnan, Lotze, \& Becich, 2014) or African American educators (Karpinski, 2006). Wanting employees with such characteristics, firms can develop pipelines to help build a targeted pool of applicants.

Additionally, labor markets that have scarcity of some characteristic are described as thin (i.e., the demand outstrips the supply of the resource). Organizations use pipelines to thicken the supply of workers, enabling more consistent and timely hiring for particular positions when the need arises (Cappelli, 2008b; Roth, 2007). Thin markets are particularly problematic when the lead time to thicken the market (i.e., develop the supply) spans years or decades. If workers need to acquire particular 
credentials and build expertise through lengthy, time-intensive training and practice but firms have demand for the skills now, a shortage can exist without an immediate solution. Once built, pipelines can provide a steady thick supply of candidates ready for just-in-time staffing when a vacancy materializes (Charan, Drotter, \& Noel, 2010; Clewell \& Villegas, 1999; Conger \& Fulmer, 2003). Thus, pipelines that increase supplies of human capital for a particular firm or set of firms may be particularly advantageous in thin labor markets.

While acknowledging these commonalities across all pipelines lends greater coherence to the pipeline concept, it is clear that differences in emphasis on these dimensions exist. Two questions arise from this observation: 1) What are the different types of pipelines? 2) What are the advantages of one type of pipeline over another? We turn to these questions next as we lay out the logic for a theoretically driven typology of pipelines.

\section{PIPELINE TYPOLOGY}

Though labor markets have always been considered a special case of a strategic factor market for organizations, recent scholarship has pushed our understanding of staffing and acquisition of human capital toward a labor market imperfections lens (Campbell et al., 2012; Chadwick, 2017; Mahoney \& Qian, 2013). Labor market imperfections are defined as deviations firms face from a perfect, unfettered competition for employees, ${ }^{3}$ and thus allow for the realization of rents from an employment transaction (Barney, 1986; Chadwick, 2017; Porter, 1980). Because labor markets vary widely according to geography and occupation, so too do the types of imperfections endemic in each market. Common labor market imperfections include firm-specificity of human capital, information asymmetries, preferential access to portable skills, supply-side market thinness, cooperative relationships between market actors, and institutional pressures from stakeholders.

These imperfections drive the suitability of pipelines for particular firm contingencies. Specifically, we observe that the major imperfections faced in any given market influence the type of pipeline that is likely to emerge. Of course, firms need not hire

\footnotetext{
${ }^{3}$ Stigler (1957, p. 14) defined perfectly competitive markets as those that have "indefinitely many traders (no one of which controls an appreciable share of the market) acting independently ... [and where] the traders have full knowledge of all offer and bid prices."
}

through pipelines. The general labor market is always available through widely accessible and at times cost-effective means such as external Internetbased job postings or other approaches to attract a broadly sourced candidate pool. Using such tactics allows firms to systematically refrain from pipeline hiring or to use both pipelines and general labor market sources in concert. If staffing is not particularly problematic or the strategic nature of the position being filled is low, or if pipelines are too costly, not timely enough to develop, or not beneficial in totality to merit their development and maintenance, firms are likely to forgo pipeline investments and practices in lieu of broad market staffing.

If pipelines engender strategically relevant crossfirm human capital heterogeneity through betweenfirm variation in sourcing and accumulation, those human capital stocks can be a source of competitive advantage for firms (cf. Barney, 1991; Brymer et al., 2014). Hence, barring nonrational action by firm decision makers, human capital pipelines would not exist in the absence of labor market imperfections because firms' best course of action would be to use the unfettered spot market for labor. In other words, pipelines exist to help firms manage labor market imperfections, and thus, the varieties of pipelines we observe in practice stem from the variety of imperfections firms encounter and at times leverage in different labor market segments.

Our review revealed three general types of pipelines that vary by scope within and between firms: internal, external hiring, and market thickening. Internal pipelines involve patterned sourcing exclusive to internal labor markets and are contained within one firm. External market pipelines typically involve two organizations: the hiring firm and either the source firm (Brymer et al., 2014) or a labor market intermediary (Bonet et al., 2013). Finally, marketthickening pipelines typically involve a group of organizations cooperating to increase the supply of workers in a particular labor market or niche within one. These types are described in Table 2, which lists each type, the labor market imperfections each addresses, and some illustrative examples.

It is worth noting that while the majority of reviewed articles discussed pipelines that fit neatly within one of these three types, a few pipelines had attributes of two types. Further, because each labor market is unique and has its own configuration of imperfections, a particular pipeline might well address an imperfection outside what a typical one of its type would, or it might address an idiosyncratic imperfection not discussed herein. This is to say that 


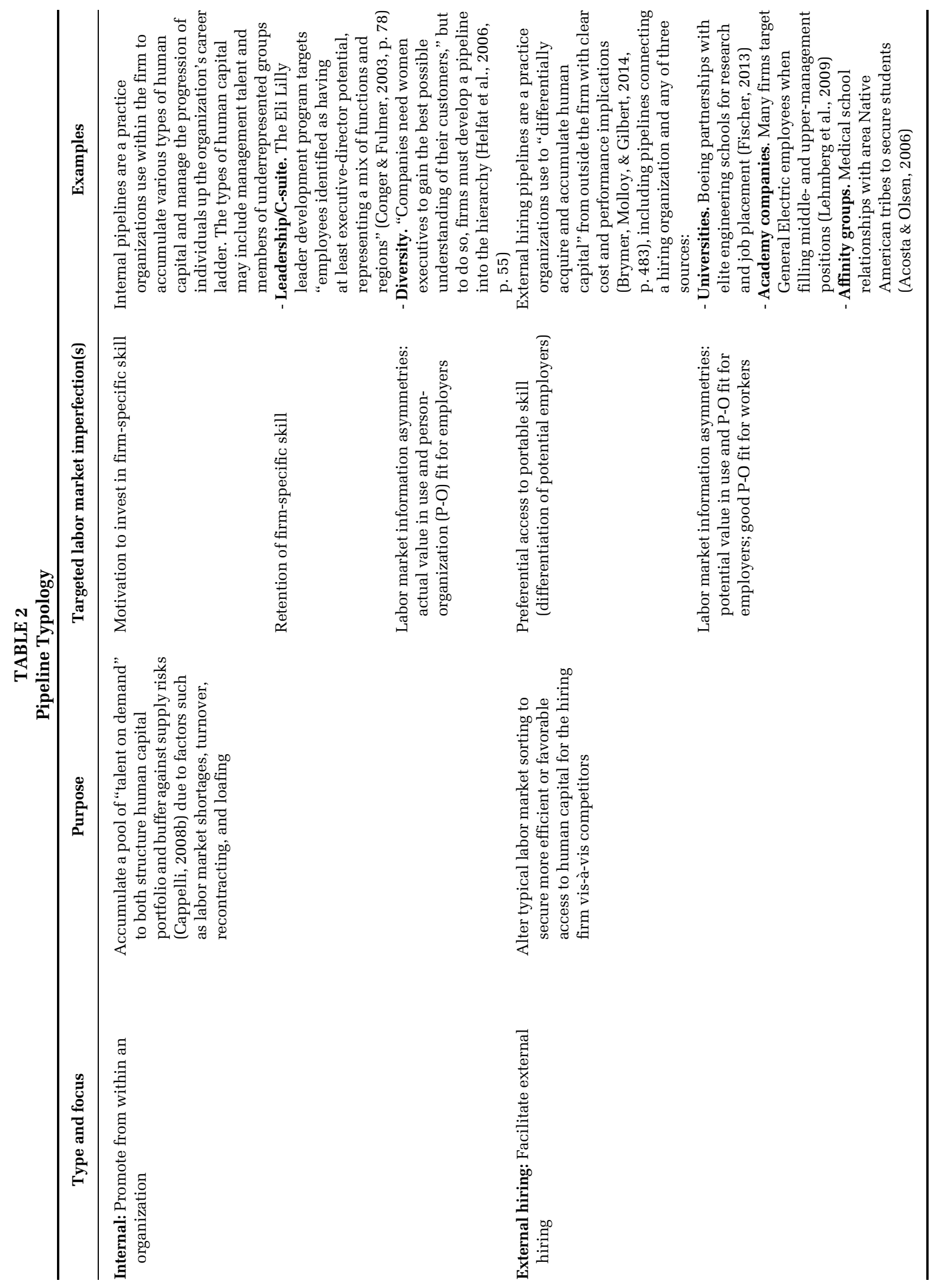




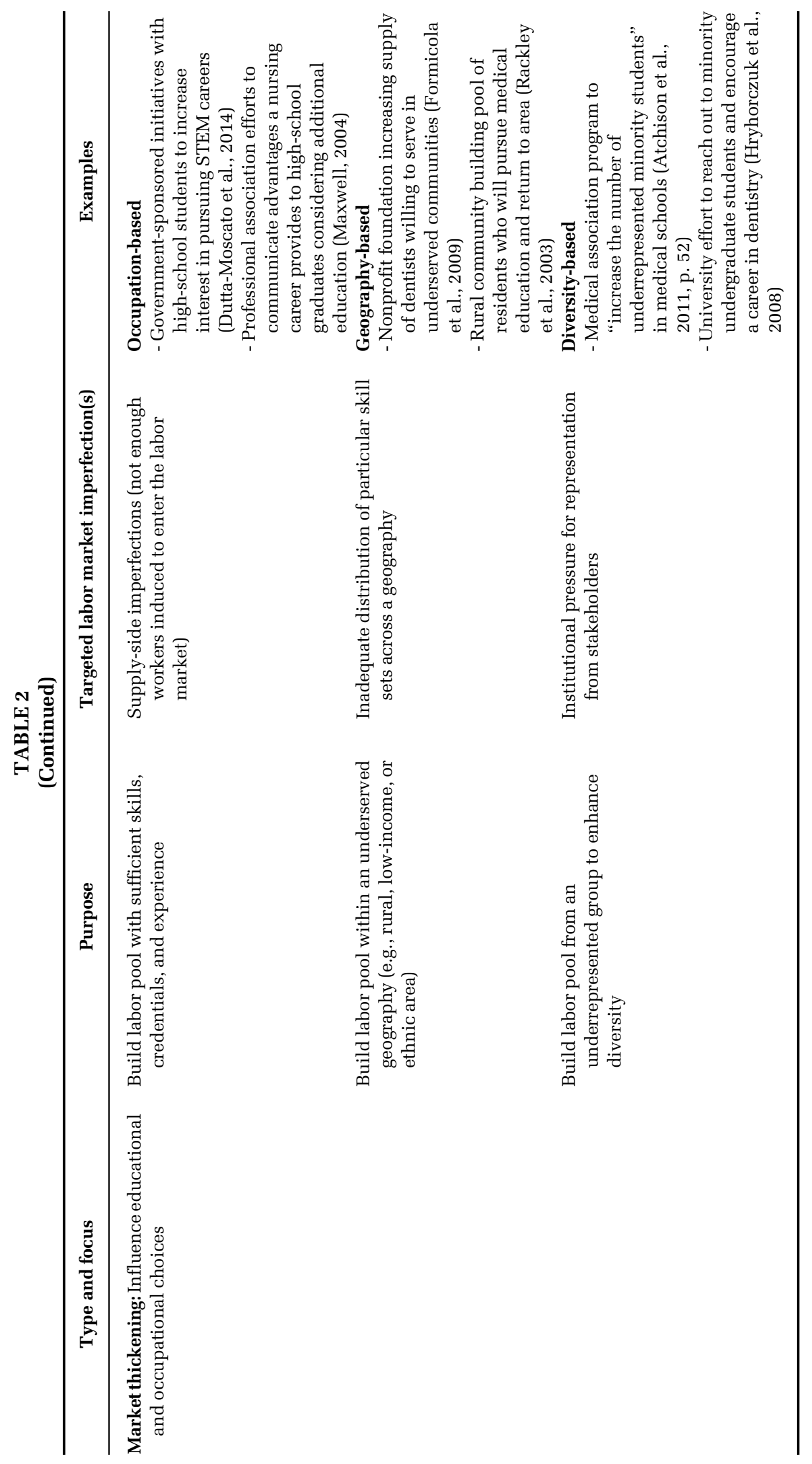


sorting the variation in pipelines to these three general categories with associated imperfections is neither seamless nor absolute. However, the typology is a key initial step in making sense of the broad category of pipelines and how firms use them to mitigate staffing challenges.

\section{Internal Pipelines}

When workers make firm-specific investments in an employer, value accrues to the firm in the form of both additional value-in-use above a worker's remuneration and as a potential source of competitive advantage with respect to rivals (Chadwick, 2017; Hatch \& Dyer, 2004). Yet it is a challenge for firms to induce firm-specific investments from their workers because investments in more general human capital typically create wage increases due to higher value at many firms that bid as employers. Thus, imperfections in the market motivate both the worker to invest in firm-specific human capital and the firm to retain that worker to capture the value of said investment. Further, workers inside the firm demonstrate their value-in-use, making it known to managers within that firm. With potential external hires, value-in-use for a particular employee faces the challenges of asymmetric information, as it can be more difficult to determine ex ante how well a particular bundle of human capital will perform with an idiosyncratic organizational context. Determination of personorganization fit with internal employees is less costly to ascertain due to these imperfections that favor development of a strong internal market.

Internal pipelines emerge largely to address these labor market imperfections. They facilitate movement of workers within an organization for future leadership or functional expertise roles by connecting those making promotion and hiring decisions with a pool of qualified candidates in the firm (e.g., Cappelli, 2008a; Conger \& Fulmer, 2003; Ulrich \& Smallwood, 2007). These pipelines consist of workers the firm may transfer or promote when needs arise. Internal pipelines differ from broader internal job boards and open searches that consider all internal candidates equally. Instead, internal pipelines create patterned movement by preferentially staffing individuals from particular groups, such as participants in internal management rotational programs or middle managers in specific functional areas. Typically, these pipelines identify high-potential talent at lower levels of the organization and provide clear, fast-tracked promotion pathways and developmental opportunities that workers would otherwise not receive. Due to these improved opportunities and demand-side constraints such as seniority-based compensation and benefits levied by firms (Campbell et al., 2012), workers are induced to stay within the firm.

Hence, talent with higher potential advances through these pipelines, reducing the likelihood of exit to other firms. Firms often invest heavily in internal pipelines to ensure that they have an in-house pool adequate to match specific jobs, thickening the internal labor market to guard against the depleting effects of turnover (Brymer \& Sirmon, 2018), especially when firm-specific skill requirements are high. Such processes over time also address information asymmetries as the firm accumulates information about how a worker's human capital fits into the firm's value-creation processes. Cumulatively, internal pipelines buffer the organization from the external market not only by developing necessary supply and allowing both quicker and more informed staffing decisions, but also by endearing workers to the organization and lessening the likelihood that workers will voluntarily exit the firm (Campbell et al., 2012).

Internal pipelines can also sequentially develop more diverse pools of qualified candidates. For example, many universities-facing shortages in female, ethnically diverse, or racially diverse faculty members and administrators-are developing pipeline programs targeting these underrepresented populations to help members advance through various stages from untenured faculty member to tenured faculty member to administrator (Pell, 1996; Stewart et al., 2008).

\section{External Hiring Pipelines}

Due to growth, turnover, and replenishment, firms need to engage the external market to bring in employees on a regular basis. In doing so, they face imperfections different in nature and scale than those faced in internal labor markets. Because the external market for qualified candidates can be many times larger than an internal market, firms face high search costs for new workers and the information asymmetries associated with broad search. Those workers' fit with the organization can be hard to discern. Workers also face this challenge in external markets. Faced with an array of potential firms where they could use their talents, workers have information challenges in knowing where they might create the most value and find the best fit.

Complicating these issues of fit, labor markets are dynamic and underlie shifts in the human capital 
characteristics firms need. New needed characteristics often do not match current internal labor markets, and firms cannot staff an infinite number of employees to develop within internal labor markets due to cost considerations (Cappelli, 2008b). Industry dynamism and labor cost pressures are arguably more prevalent now than in the past, underscoring the need for firms to manage these pipelines strategically. The unforeseen shifts in needed employee characteristics motivate firms to staff at an optimal level internally while also having the potential to tap employees outside the firm in an efficient manner.

Individuals in the external market have portable human capital. In unfettered labor markets, a firm must compete with all other firms for access to and attraction of that human capital (Breaugh, 2008). Large reputable firms with recognizable brands enjoy decided advantages in drawing applicant interest and attraction (Collins \& Han, 2004). Firms competing with such advantaged incumbents face imperfect price competition, where workers may prefer those large reputable firms for quality signaling and for development opportunities, despite the fact that often these firms pay less than lesser known rivals (Bidwell et al., 2015; Bidwell \& Briscoe, 2010).

Firms often react to circumvent these imperfections by creating external hiring pipelines (Brymer et al., 2014). External hiring pipelines connect an employer with a particular source-a subset of the available labor market. Labor sources can be educational institutions, academy companies, affinity groups, search firms, temp agencies, and other labor market intermediaries (Bonet et al., 2013). These pipelines establish preferential access and enable repeated and disproportionate hiring of workers from the source (relative to the labor market as a whole). Because these pipelines are quasi-market, providing many of the information and attraction advantages of internal pipelines, external hiring pipelines provide resolutions in markets commonly plagued with asymmetric information, entry barriers, and path-dependent advantages of large rivals. These pipelines circumvent imperfections of preferential access to candidates, isolating the firm from competitors by favorable connection with a particular source of candidate, ultimately favoring firms with these pipelines (cf. Barley, 1989; Dobrev, 2005).

Intriguingly, these pipelines have "the potential to facilitate FSHC [firm-specific human capital] development even prior to the onset of a formal employment relationship" (Brymer et al., 2014, p. 496; emphasis in original; cf. Campion, Ployhart, \&
Campion, 2017). For example, Osterman and colleagues highlighted how firms may establish relationships with community colleges and universities to help develop knowledge about and skills for employment with the firm post-graduation (Osterman, 2011; Osterman \& Burton, 2006; Osterman, Kochan, Locke, \& Piore, 2002). Similarly, as pipelines establish repeated hiring from the same source, individuals coming through pipelines are likely to have social capital with individuals in the firm who previously went through the same pipeline, facilitating communication of firm-specific information and practices (Campbell, Saxton, \& Banerjee 2014; Coleman, 1988; Garbuio, King, \& Lovallo, 2011). By facilitating acquisition and accumulation of firm-specific social capital, external pipelines can benefit both firms and individuals in the pipelines. Firms are able to push some development practices and associated costs to external entities (Gardner, 2005), and individuals in the pipeline are able to garner additional insight into the FSHC necessary at a given employer and better assimilate post-hire.

At the same time, external pipelines help address market imperfections associated with changing demand and optimal employment levels by operating as a form of organizational slack-the firm can tap the pipeline when needed while operating more efficiently by not keeping excessive levels of employees on payroll. This buffers potential future labor market shifts by establishing a real option type relationship in the form of pipelines that can be more heavily leveraged when needed.

\section{Market-Thickening Pipelines}

In any given geography, occupation, or industry, there can be shortages of workers. When firms need to hire workers whose human capital needs to be built over years-such as with most knowledge workers, managers, and specialized laborers-labor shortages might persist because of the lead times necessary to address them. Institutional pressures for workforce diversity can also cause shortages of qualified workers from particular underrepresented groups, such as women who lack top management team and board member experience (Brands \& Fernandez-Mateo, 2017; Helfat et al., 2006).

Because these shortages tend to cut across many firms nested in geographies, occupations, and industries, we encountered an interesting phenomenon in our review of pipeline scholarship: cooperation among many market actors to build a deeper supply of niche workers available for multiple 
firms to hire. Characteristics of these marketthickening pipelines have at least three implications: 1) While ultimately, the individuals in these pipelines are employed by organizations, this pipeline type differs from the previous two general types because it is not specific to any one firm; 2) the scope of market-thickening pipelines can be quite broad, encompassing multiple cooperating organizations, some of which may even be fierce product market competitors, and others of which may exist in the nonprofit or governmental sector but nonetheless provide benefits to the for-profit firms; and 3) positive externalities, such as improved access to health care services or greater minority representation in important societal roles, are common for this type.

Market-thickening pipelines combat labor market imperfections of labor supply shortages and institutional pressures from various stakeholders. Specifically, they guard against future worker shortages in specific occupations (e.g., skilled labor), diversity representation (e.g., historically underrepresented groups such as women and racial minorities), and traditionally underserved geographic areas (e.g., rural areas or Native American reservations). When thin markets are the result of supply-side imperfections that inhibit workers from entering the labor market, such as time-compression diseconomies in developing particular skill sets, market-thickening pipelines are primarily intended to combat inadequate human capital supply that can inhibit firms' operational effectiveness. For example, to combat the inadequate pipeline of workers available in various science, technology, engineering, and math (STEM) fields, the U.S. government has established the Committee on STEM Education, or CoSTEM, a multi-organizational initiative aimed at increasing the number of proficient students, teachers, and eventual workers in these fields (U.S. Department of Education, 2016). CoSTEM involves governmental organizations coordinating with various for-profit firms, nonprofit organizations, and educational systems to increase the future supply of available U.S. STEM workers (cf. Dutta-Moscato et al., 2014).

In other cases, the primary intent of marketthickening pipelines is to target inadequate distribution of human capital over a certain geography, or to respond to institutional pressures from various stakeholders for greater representation of their group in a given profession or industry. For example, Native American nonprofit organizations build pipelines to help ensure that their communities will have medical professionals willing to work with their tribes and possibly relocate to the region upon graduation from medical training programs (Acosta \& Olsen, 2006).

Organizations that cooperate in building marketthickening pipelines engage individuals early in career development stages and often encourage their movement into a career, such as by providing funding and offering programs aimed at getting future workers into the pipeline. Hiring organizations may facilitate goodwill and loyalty in these early stages, which in turn improves their access to trained workers when needed in the future. For example, the largest accounting firms actively engage high school students to improve the visibility and attractiveness of a career in accounting. Specifically, programs include KPMG's participation in the Accounting Career Awareness Program to increase the number of underrepresented minorities in the profession (National Association of Black Accountants, 2017), Deloitte's leadership in the Center for Audit Quality to thicken the future market for auditors (Center for Audit Quality, 2017), and Ernst \& Young's participation in many outreach programs for a variety of affinity groups (Ernst \& Young, 2017). Importantly, market-thickening pipelines are distinct in not providing any single firm sole preferential access. Rather, all participating organizations accrue benefits via disproportionate selection with respect to all competitor firms that do not participate to support the pipeline. By virtue of differential participation within the pipeline, participating firms can foster varying degrees of engagement and attraction with the targeted individuals in the pipeline that can be used for advantageous future recruitment.

\section{General Observations From Constructing the Typology}

All pipelines can influence cross-firm heterogeneity in human capital accumulation, and pipelines can be categorized along the dimensions we discussed above. The point of the typology is to establish clear terminology in reference to the various ways scholars refer to pipelines. The typology and accompanying definitional clarity, in turn, offer a pathway to build cumulative knowledge within this emerging literature stream. By nature of their repetition, pipelines are longterm sourcing options that increase the predominance of certain types of human capital in the organization at the expense of others. In this way, the formation of pipelines can determine the mix of human capital in the organization. Time compression diseconomies provide isolating mechanisms for accumulating this human capital (Dierickx \& Cool, 1989). 
For instance, Textron, a U.S.-based aerospace, defense, and technology firm, historically staffed positions through the broad external market by posting openings on widely available sites. After a new CEO was hired in 2009, Textron ended these staffing practices in favor of building pipelines to about a dozen universities and developing rotational and management leadership programs internally for the most promising early hires. Now middle and upper management at Textron are staffed almost exclusively through internal pipelines. This talentsourcing strategy has fundamentally shifted the types of workers hired at the firm, in turn changing the potential firm capabilities and cross-firm human capital differentiation (Ployhart \& Moliterno, 2011). Competing firms now face a more difficult challenge if they want to imitate Textron's human capital resources because of the time compression diseconomies of establishing similar pipelines and greater degrees of causal ambiguity in Textron's selection and development of human capital.

In this way, firms may purposefully leverage imperfections in the labor market that provide isolating mechanisms and differentiation with respect to competitors (Kerr, 1977; Peteraf, 1993). In the short term, pipelines may not generate net benefits for the firm, as the resource outlays necessary to build a pipeline can eclipse immediate benefits. Pipelines may instead be viewed as real options investments in creating a differentiated workforce in the future (McGrath, Ferrier, \& Mendelow, 2004); organizations may invest in a pipeline that is inferior in addressing imperfections in the short term, yet that pipeline might provide improved future access to talent from a particular source. For instance, a firm might get more immediately effective workers from a contractor firm but choose instead to accumulate the skills and worker type from a particular specialized university program to create a cadre of workers with high complementarity to one another. As firms accumulate workers through these more strategically oriented pipelines over time, differentiation from competitors is possible by creating a critical mass of workers with particular characteristics within the organization and locking out competitors from pools of labor with those characteristics (Brymer et al., 2014).

These proactive approaches to building pipelines ameliorate future shortages. When a shortage is anticipated, a pipeline that provides privileged access to workers buffers the firm both from overpaying for scarce external candidates and from an inability to hire enough qualified workers in the future. In this scenario, a firm with a pipeline can realize a competitive advantage when the labor market shifts (e.g., a strong economy with lower unemployment). Pipelines can preempt these potential problems and provide staffing slack against the downsides of market shifts. For example, Lockheed Martin continues hiring from university partner programs even in economic downturns when the internal need for labor does not justify it. By maintaining these pipelines, Lockheed Martin enjoys improved access to the most talented in those programs throughout the business cycle (Evans, 2010), which presumably provides the firm higher value-creation potential than would be realized by hiring from the general market (Chadwick, 2017). We now turn to describing how firms can manage sets of pipelines strategically in these and other ways.

\section{PIPELINE PORTFOLIOS AND BETWEEN-FIRM HETEROGENEITY}

As the previous section suggests, firms have an array of pipelines to employ, in terms of both the general pipeline types (e.g., internal labor markets or external pipelines) and the many different specific pipelines within the same general type (e.g., external pipelines to labor market intermediaries such as search firms or temporary agencies or pipelines immediately to sources, such as technical schools, colleges, or universities). How firms staff through one pipeline over another can be driven by various market imperfection types: When an imperfection hinders a firm's ability to staff effectively from a particular labor market or niche therein, one solution is to choose the pipeline that addresses that imperfection. In other words, the nature of the job vacancies and the workers who might fill those vacancies prescribes the types of imperfections faced, the magnitude of those imperfections for the staffing firm, and the pipeline(s) that is (are) most suitable to address those imperfections.

While it is clear that pipelines have the potential to help address labor market imperfections and differentiate firms from competitors, there are limitations to the benefits of any single pipeline as well as specific drawbacks. For example, internal labor markets may be good at addressing information asymmetry but less efficient at thickening a labor market segment and deferring training costs to employees. Developing external pipelines to colleges and universities transfers many training costs outside the firm and can help thicken markets more efficiently, but it does not address information asymmetry as well as internal pipelines. Table 2 above highlights 
some of the trade-offs associated with specific pipelines.

The costs and potential benefits of leveraging labor market imperfections with particular pipelines vary as well. For example, when information asymmetries largely concern potential, attitude, and intrinsic characteristics because workers are early in their careers, pipelines from partner university programs may be sufficient to generate needed information for staffing choices. In these cases, firms establish formal internships and co-programming that allow a preview of applicants as they complete agreed-upon internships and projects. In other cases where firmspecific skill and understanding of a firm's business are more critical, the greater investment required by internal pipelines is warranted. Both pipelines help firms manage information asymmetries, but the advantage of one over another is driven by differences in the particular types of information asymmetries the firm faces.

Two related issues complicate firms' leveraging of labor market imperfections with pipelines. First, firms do not face only a single labor market imperfection but rather many potential imperfections simultaneously, even for a single position. A single pipeline may not be well suited to address all imperfections effectively, and therefore firms may need to employ multiple pipelines simultaneously, such as using both internal pipelines and external hiring pipelines to universities. Second, because firms have different market positions and operate in various geographic markets, different pipelines are best fitted to those conditions. Consider developing countries where formal education and trade organizations are not as plentiful. In this context, a firm may not be able to develop pipelines to these sources of human capital, and may instead need to rely more on internal pipelines to develop the needed human capital and/or develop pipelines to a kinship organization for help in securing preferential access to employees.

\section{Pipeline Portfolios}

Pipelines do not have a simple one-to-one correspondence to labor market imperfections. Rather, firms may choose to employ multiple pipelines simultaneously to optimize their combined strengths. Consider, for example, the shortage of female executives and the extensive vetting that comes with executive staffing, which generally renders the spot market for labor ineffective for various reasons. Firms often develop internal pipelines in an effort to build a pool of qualified female applicants to advance, and yet there are still leaks in these internal pipelines (Brands \& Fernandez-Mateo, 2017). To combat leakage and deepen the applicant pool, firms can develop pipelines with search firms to help identify qualified females external to the firm, but such partnerships also suffer from leakage in the form of self-selection and hiring biases that hinder the effectiveness of such pipelines (FernandezMateo \& Fernandez, 2016). When used in concert, the two pipelines help firms staff qualified female executives and, at the same time, may create complementarities that enhance the value of each pipeline when used in combination. The same firm may also wish to help establish or participate in a market thickening pipeline to help more female applicants enter and remain in the executive pathway. Though these pipelines may work well in concert for female executives, they may not be optimal for entry-level labor. A pipeline to a university may be better suited to staff these positions and a market thickening pipeline may or may not be necessary, depending on the market.

Thus, we propose that different labor market imperfections in various labor market segments give rise to the use of a mix of pipelines to staff human capital across the enterprise. In essence, firms require their own unique mix of pipelines to ameliorate value-destroying imperfections, to leverage imperfections that build strategic differentiation, and to manage sourcing across the enterprise. We refer to this mix of pipelines a firm employs as its pipeline portfolio.

Although the concept of pipeline portfolios is perhaps intuitive, much of the staffing, recruiting, and selection research to date has confined itself to examining the efficacy of a specific mechanism (e.g., referral hiring), staffing of a specific position (e.g., CEO selection), or use of a particular tool (e.g., tests of individual differences; see Phillips \& Gully, 2015). While such focused research tends to be quite rigorous, broader studies that consider the multidimensional nature of enterprise-wide staffing can provide more holistic insights for discerning firm-level human capital accumulation tendencies via the mix of potential sources. Thus, in addition to evaluating the effectiveness of any one type of pipeline, we have much to gain by examining the characteristics of a firm's pipeline portfolio, such as the total number of pipelines, the types of pipelines, the breadth of pipelines, the relative strengths and weaknesses of pipelines, and the complementarities among pipelines. Without broadening our 
perspective to consider pipeline portfolios, we may paint inaccurate pictures of how firms create heterogeneity among themselves and other firms.

\section{STRATEGIC PORTFOLIO MANAGEMENT}

As we noted above, the probability of a single pipeline addressing a set of labor market imperfections in its entirety is low, so firms may attempt to mitigate the weaknesses of any single pipeline by developing a portfolio of pipelines. In other words, effective imperfection-pipeline matching is enhanced by having a variety of pipelines to draw on. Because the success of any single pipeline is uncertain and thus poses risks, firms avoid relying on only one source of human capital (Bidwell, 2011; Bidwell \& Keller, 2014; Cappelli, 2008b; Hamori et al., 2011). Instead, firms typically attempt to spread the risk by investing in multiple pipelines for any particular position and, more important, for positions across the firm. A pipeline effective for sourcing female executives (e.g., internal development, search firms) may be ineffective for entry-level positions. Conversely, effective pipelines for entrylevel vacancies (e.g., partner programs with universities, temporary agencies) may not work for sourcing female executives. The matching hazards compound with stronger and more numerous labor market imperfections. Thus, we posit that firms employ a wider variety of pipelines when they face labor markets that are far from perfectly competitive. Further, we offer insights on some of the more pressing issues that firms face and how portfolios can work to address them.

\section{Stability, Dynamism, and Mobility}

When external environments are highly stable, the value of having many options in a pipeline portfolio will decline because fewer matches to labor market imperfections are needed, and new matches to imperfections are not needed as quickly. In other words, in stable conditions firms are likely to have narrower portfolios because the imperfections they need to address are more predictable and less varied. As a result, the firm is unlikely to spread pipeline investments and instead will likely target a narrower set of sources to develop human capital. In particular, we expect that such firms will invest more heavily in internal pipelines, developing firmspecific human capital. Conversely, highly uncertain and dynamic environments will beget broader portfolios of pipelines as firms attempt to shield themselves from the vagaries of the market by having more pipelines to tap for workers when needed. With access to labor less certain in dynamic labor markets, firms may wish to establish broader portfolios to guard against possible shortages because they have less certainty from period to period about what their labor needs may be. Developing a portfolio of pipelines to various sources and various diverse labor pools allows firms more flexibility in responding to dynamic conditions.

Firms do not have total control over workers' employment choices (Coff, 1997; Peteraf, 1993). Even if pipelines develop human capital that is valuable now, the mobility of workers across firms or occupations is a special form of labor market dynamism firms must combat. Firms with more mobile workers-such as those with portable skills or those willing to relocate-face greater threats of workers leaving and therefore may have a stronger need to develop pipelines to guard against attrition. Certain industries have higher historical turnover, such as those with stressful jobs (Podsakoff, LePine, \& LePine, 2007) and those associated with "dirty work" that is stigmatizing because job tasks are physically, socially, or morally tainted (Ashforth, Kreiner, Clark, \& Fugate, 2007). Such firms need broader portfolios. And because mobility issues tend to confront entire industries, market-thickening pipelines may be particularly appropriate.

General market dynamism and worker mobility require buffering internal pipelines with a portfolio of other human capital sourcing approaches. Developing multiple sources in advance (creating pipeline portfolios) helps to shield the firm from labor market risks. To generalize this point, all else being equal, we expect that the difficulty of making good matches between pipelines and labor market imperfections increases with dynamism and uncertainty in a firm's product and human capital markets as well as with the mobility of workers. Conditional on such factors, we argue that firms employing a variety of labor market pipelines are more likely to make good matches with labor market imperfections. Firms wishing to leverage pipelines in the future should invest now in a broader portfolio-particularly one providing access to different sources of skills and knowledge-to hedge risks associated with exogenous shocks.

\section{Homogeneity and Diversity}

Another issue that pipeline portfolios can combat is increasing within-firm human capital homogeneity 
and associated inertial and institutional risks. Absent intervention, constituents of firms, occupations, and industries typically become homogenized over time (Schneider, 1987; Spender, 1989). Ultimately, human capital homogenization within a firm entails both benefits and costs. Homogenization provides greater bundling flexibility, as more interchangeable individuals are available when promotion or turnover occurs, providing stability (Brymer \& Sirmon, 2018). Homogenization can result in better personjob fits, facilitate higher satisfaction and lower turnover, and yield better predictability of human capital for firms. Yet homogenization decreases creativity and diversity, causing a variety of related problems.

Many specific pipelines can accelerate homogenization as similar individuals select into, and different individuals leak out of, any single pipeline. The pipeline also develops individuals in a specific way. However, pipeline portfolios can combat such homogenization in three ways. First, as any single pipeline creates human capital homogenization for the staffing firm, establishing multiple pipelines to different sources creates human capital heterogeneity within the firm. Second, one pipeline to a source that has high consistency in worker type might offer a type that is very different from the workers already in the organization. For instance, many U.S. firms that have disproportionately high levels of white employees create pipelines to historically black colleges and universities (HBCUs) to become more racially diverse. Finally, firms can create diversity by intentionally cultivating a wide range of pipelines, each targeting distinct and different characteristics of human capital. Thus, the choice of which pipelines in a pipeline portfolio to cultivate is fundamental to long-term diversity within the firm. To the degree that heterogeneity is advantageous, such as in increasing creativity, improving problem solving, signaling the market, and satisfying stakeholders, a portfolio-level view of pipelines benefits firms.

While many pipelines undoubtedly emerge simply as a means to combat labor market imperfections, firms may also be able to generate legitimacy from the homogeneity (e.g., Ho, 2009) or diversity (e.g., Helfat et al., 2006) that pipelines generate. Firms in older stable industries may have longstanding pipelines that help ensure that the firms have adequate labor. Nascent firms, firms in emerging industries, and firms that need specialized labor not generally demanded in the market may develop pipelines both to confer legitimacy and to generate advantages.

\section{Portfolio Management Capabilities}

Our arguments emphasize the importance of fitting pipelines and portfolios to labor market imperfections and the strategic value of doing so. Each pipeline offers advantages and disadvantages that vary with firm contingencies, particularly with imperfections, and thus we propose that a typical firm cultivates a portfolio of pipelines that facilitates effective matching between pipelines and imperfections. Using multiple pipelines allows a firm to overcome the limitations of any single pipeline as well as the associated risks of staffing with a single approach. Further, we suggest that firm contingencies such as those outlined above can influence not only the value of individual pipelines, but also the optimal configuration of a firm's portfolio of pipelines. It is probable that firms vary in their abilities to configure their pipeline portfolios, particularly in the face of time compression diseconomies, uncertainty, and the ability to combat potential nonstrategic factors lacking clear benefit that drive the emergence of portfolios.

In other words, pipeline portfolios draw our attention to variance in firms' ability to arrive at, and manage, a set of relationships with human capital sources as well as to pipelines themselves. This strategic capability takes at least three distinct forms: imperfection matching, pipeline implementation capabilities, and diversification of pipelines.

Imperfection matching. With uncertainty in the competitive environment now and in the future, firms vary in their ability to match imperfections to pipelines. Because pipeline development is a resource-building activity that takes time, firms have to place bets on their future pipeline needs. Other things being equal, firms that are better at making these bets in the aggregate, either by luck or by superior strategic intent, can reap persistent benefits. For example, a firm may be less effective at creating value through any single pipeline but more effective than competitors in sourcing human capital overall by combining multiple pipelines' strengths and using their complementarities effectively. Thus, a firm's capability to effectively configure its pipelines could be considered a subset of the human capital management capabilities that have recently been argued to underlie firms' human capital rents (Chadwick, 2017) —and, more broadly, one type of entrepreneurial foresight that drives long-term firm rents.

Pipeline implementation capabilities. A second type of pipeline portfolio capability is in implementation. Human resource management scholars 
have documented differences in firms' abilities to implement HR practices of many kinds (Sikora \& Ferris, 2014). Such differences would presumably manifest regarding the implementation of pipelines as well. Pipeline implementation effectiveness could mitigate less than perfect matches between pipelines and labor market imperfections. Thus, we view these two types of pipeline capabilitiesmaking good matches to imperfections and implementing pipelines effectively-as potential substitutes and complements with respect to firms' human capital rents. Accordingly, one question for future research could involve defining the circumstances under which substitution and complementarity occur. It is possible, for instance, that poor implementation is more impactful than excellent implementation, such that the relationship of a firm's pipeline implementation capability with human capital rents is nonlinear.

Diversification of pipelines. Third, the pipeline portfolios concept raises the question of decreasing marginal returns. Clearly, the direct cost of cultivating numerous pipelines will generally be greater than the cost of cultivating fewer pipelines. Hence, the benefits of maintaining a portfolio of pipelines must be worth the cost to firms, and at some point, the marginal costs of implementing another pipeline will exceed the benefits. The cost/benefit ratio associated with diversifying the portfolio is likely to be positively associated with the value of helping the firm address one or more of its key problems, be those operational, strategic, or institutional. This diversification logic also applies to specific sets of pipelines, of course, such as the choice that a firm faces in how many universities it maintains recruiting relationships with.

The cost/benefit ratio of a pipeline portfolio is a function of individual pipelines' aggregate cost/ benefit ratio, of overlap between the value that different pipelines deliver to the firm, and of complementarities among different pipelines. If pipelines in a portfolio are largely redundant because they are multiple avenues for securing the same type of human capital for the firm, the cost-effectiveness of the portfolio as a whole will be low. If, on the other hand, the portfolio gives the firm preferential access to different types of human capital (controlling for the pipelines' abilities to address different labor market imperfections), the strategic value of the portfolio will be higher. This value can also be enhanced by complementarities among pipelines that increase the value rendered by the portfolio above the simple sum of its individual pipelines' effects.

\section{Interactions of Pipelines in Portfolios}

Consider, for example, the paucity of female executives mentioned earlier (Brands \& FernandezMateo, 2017; Helfat et al., 2006). Firms can combat this issue by developing internal pipelines to cultivate talented female managers. Some firms doubtlessly do this more successfully than others. Hence, a firm's capability to construct an effective female leadership pipeline will contribute to its human resource positions. Yet as Fernandez-Mateo and Fernandez (2016) noted, such internal development programs may not be as effective as firms expect because women in these pipelines have a higher likelihood than men to either voluntarily leave organizations prior to promotion to the C-suite or to remain in the organization but self-select out of consideration for executive positions (i.e., they voluntarily exit the internal leadership pipeline). Thus, firms seeking to employ female executives may combine internal development with hiring pipelines from academy companies (Brymer et al., 2014), partnerships with affinity organizations like Catalyst that seek to promote the advancement of women in executive positions (Beeson \& Valerio, 2012), and repeatedly engaging search firms that assemble deep pools of qualified female candidates (Cappelli \& Hamori, 2014).

Establishing patterns of staff sourcing may have both first-order and second-order effects: Not only does the firm gain access to a supply of human capital and potentially preclude nonstrategic decisions that are not of value (first-order effects), but the firm also gains ancillary connections to other organizations (second-order or complementarity effects). Firms that effectively manage the networks of workers, both within and outside the firm, associated with portfolios may be able to gain these additional second-order benefits. Because of the repetitive nature of pipeline staffing, firms can create embeddedness with external organizations and strengthen alliance ties.

Consider how sources of labor such as trade schools and universities may use eventual job placement as a marketing tool for the purpose of enrollment. In turn, the eventual employer becomes a valuable partner for the school/university, further embedding the pipeline and begetting additional advantages to the firm. These second-order effects are not limited to hiring firms. Organizations that develop human capital, such as academy companies and universities, foster recruitment of their constituents to realize benefits due to placement (e.g., Carnahan \& Somaya, 2015; Somaya et al., 2008). 
Examples include McKinsey's alumni network and universities' corporate partnerships that provide reliable placement of graduates. In both instances, the benefits from the pipeline extend beyond the simple increase in matching on the labor market (first-order) to additional benefits that result from the relationship (second-order).

In short, from the broader perspective of pipeline portfolios, heterogeneity in human capital across firms stems from broad cross-organizational differences in human capital acquisition and accumulation processes (Maritan \& Peteraf, 2011; Sirmon et al., 2007; Wernerfelt, 2011), both in the efficacy of implementing individual pipelines and in the firm's ability to choose pipelines to include in its portfolio. Consequently, beyond simple acquisition and accumulation benefits of pipelines, variation in ability to manage portfolios provides avenues for potential differentiation among competitors.

\section{DISCUSSION}

The great ancient Chinese general Sun Tzu once stated, "Victorious warriors win first and then go to war." Echoing this idea, our theory suggests that firms can win the "war for talent" not only by competing contemporaneously for human capital once it has entered the labor market, but additionally by developing pipelines and portfolios that provide favorable access to talented workers before negotiations for staffing those positions commence. In other words, firms actively shape their labor markets and address their imperfections with pipelines, targeting constituent labor sources and etching preferential pathways in advance of the need to staff particular positions.

We also argue that variation in how firms implement and select pipelines underlies between-firm human capital heterogeneity. Research concerning the fundamental question of how human capital resources are created, particularly over time and through the management of flows of employees, "barely taps the surface" of its potential (Ployhart \& Cragun, 2017, p. 144; see also Phillips \& Gully, 2015). We directly address this scholarly omission. Following the research tradition investigating the theoretical implications of heterogeneous orchestration of human resources on firm performance (Chadwick, 2017; Lepak \& Snell, 1999; Ployhart et al., 2014; Sirmon et al., 2007), we articulate the development and maintenance of both individual pipelines and their portfolios, providing a new lens for recognizing firm-level human capital heterogeneity.
Although there are many differences in how specific pipelines affect firm performance, we note two broad distinctions. First, some pipelines' positive effects only achieve parity with competitors. For example, a firm may need to build relationships with an underserved population of workers through a market-thickening pipeline to mollify a key stakeholder, such as a local government. When the firm's competitors have existing relationships with that population of workers, the pipeline's effect is to reduce competitively disadvantageous heterogeneity. Institutional theory suggests that the most likely effect on firm performance of such mimetic isomorphism is that the pipeline helps secure necessary resources for the firm, thus increasing the likelihood of firm survival (DiMaggio \& Powell, 1983). In such cases, firms can find value by imitating the pipeline portfolios of their competitors, providing them a better likelihood of survival.

In contrast, other pipelines differentiate the firm from competitors in ways that drive economic rents. Most of this paper has focused on how pipelines create such differentiation, such as securing preferential access to specific kinds of human capital at the expense of competitors. In other words, the effects of many pipelines are to create or accentuate heterogeneity that offers a firm competitive advantage. Here, imitating other firms' pipelines would be counterproductive to the firm's interests. Rather, the firm would want to leverage competitively relevant, unique characteristics that can be the basis of differentiating pipelines and subsequently of differentiated human capital resources. The difference between the two broad types of effects on firm performance reflects differences in the types of heterogeneity that pipelines lend to their firms, and correspondingly, they reflect differences in the type of strategic value that pipelines create.

A pipeline perspective provides avenues for future research. Better understanding these staffing tools and the mix of tools in portfolios offers an opportunity to extend understanding of staffing more generally as well. Most staffing literature considers individual workers as the unit of analysis, but the portfolio perspective shifts our focus to firms and how they cultivate, differentiate, and structure their human capital resource. In doing so, our paper responds to multiple scholarly calls to strengthen the theoretical grasp on staffing, including discerning firm value derived from the staffing function (Ployhart, 2006), placing greater emphasis on the firm as the unit of analysis in staffing (Ployhart et al., 2014), theorizing mobility constraints due to labor 
market imperfections (Campbell et al., 2012), considering the implications of targeting assorted sources of talent (Phillips \& Gully, 2015), and building more depth in the potential firm-level advantages that targeted sourcing affords (Brymer et al., 2014). Thus, our contribution is at the intersection of strategy and mobility, and squarely in the strategic human capital space (Campbell, Kryscynski, \& Olson, 2017; Mawdsley \& Somaya, 2016), with implications more broadly for resource orchestration given the nature of acquisition and accumulation tools pipelines portfolios afford (Sirmon et al., 2007). The review of pipeline literature and subsequent theory suggests not only that firms are increasingly turning to these staffing mechanisms, but also that the reasons behind their creation and their subsequent firm implications differ substantially. Questions related to pipeline and portfolio scholarship arise from our work and deserve scholarly attention, as we note. While our focus is most squarely on firms and the use of pipelines and pipeline portfolios, a number of related issues arise related to individuals managing pipelines, those going "through" pipelines, and those not in pipelines. Though certainly not comprehensive, we offer a few research ideas for consideration.

\section{Individual Employee and Career Ramifications}

Pipelines have a number of implications for employees and their careers. Beyond using the traditional internal labor markets equipped with developmental opportunities that have long been a hallmark of firms' staffing practices, our review and theoretical rationale suggest that firms are increasingly leveraging repeated and targeted sourcing in the forms of pipelines with organizations external to the firm. For individuals interested in joining an occupation generally, or even working at a given firm specifically, getting a foot in the door may have greater weight now than ever before. Specifically, given that firms are increasingly leveraging pipelines and forgoing the traditional spot market for labor, participating in pipelines has the potential to disproportionately increase workers' odds of securing quality employment. Employees may be best advised not just to build their skills and knowledge, but also to take a more targeted approach by associating with organizations and programs aligned with specific pipelines.

However, like firms, workers should not always forgo a broader market job search. Because of the large number of firms that hire from the general market, workers can match with a firm and job that fit well. Alternatively, workers may derive benefits from entering into pipelines given particular labor market conditions. Workers can remove information asymmetries about possible employers by entering pipelines, gaining exposure to firms as they interact with firm representatives who manage pipelines and pipeline workers in the targeted firms. Workers may also develop valuable firm-specific human capital and relationships in a firm, improving the likelihood of fit and ultimately assimilating efficiently post-hire through pipeline participation (Brymer et al., 2014). Of course, being in a pipeline is not sufficient to secure employment for a worker or even to perform better once hired; workers will still need to perform well in the sequencing and development phases within the pipeline and on the job. But all else being equal, individuals who enter pipelines are likely advantaged compared to individuals who attempt to secure employment through a broader, unfettered open market.

Market thickening of candidate pools calls into question compensation negotiations. An individual's inclusion in the pipeline could improve her bargaining power because firms may choose to invest, in the form of a wage premium, in the pipeline's health and continuity to reap future benefits. Indeed, in a recent paper using similar logic, Marx and Timmermans (2018) found comobility of multiple workers increases their wages. Conversely, higher supplies of more homogeneous pipeline candidates give firms negotiation advantages in certain circumstances, as cluster hiring from a particular source can improve firm performance (Eckardt, Skaggs, \& Lepak, 2018). A firm with a broader portfolio also has more options and is in a stronger position to negotiate because of a higher number of available suitable candidates. Studies on the wage differentials experienced by pipeline and nonpipeline hires could yield intriguing results.

Pipelines may matter most to individuals who are not in them. Durable pipeline structures built by firms can marginalize or exclude candidates who are external to preferred labor sources. Individual applicants outside of pipelines may find it difficult if not impossible to be considered as candidates regardless of how qualified they might otherwise be (Gellman, 2015; Ho, 2009). Thus, pipeline staffing challenges notions of boundaryless careers where individuals move without barriers (Arthur \& Rousseau, 2001). ${ }^{4}$ This perspective echoes recent

\footnotetext{
${ }^{4}$ We thank an anonymous reviewer for these insights regarding the pipeline implications for individuals.
} 
work that recognizes that firm hiring practices can be quite discriminatory, though such discrimination might be against groups not otherwise tracked (e.g., socioeconomic status or academic pedigree rather than race/ethnicity or gender; Bidwell et al., 2013; Brymer et al., 2014; Cobb, 2016; Rivera, 2015). A pipeline portfolio may be designed at least in part with a desire to curb such discrimination.

\section{Nonstrategic Pipeline Portfolio Management}

In contrast to the competitive logic of imperfection mitigation and differentiation, nonstrategic factors likely drive the existence of many pipelines. (To be clear, our use of "strategic" in this context denotes activities that affect the competitiveness of the firm. To the extent that activities affect firm performance, nonstrategic factors are more influential in terms of firm survival, may hurt firm performance, or may not meaningfully affect firm performance at all. As Jorgensen and colleagues recently noted (2016, p. 2):

\footnotetext{
Strategic intent in human capital management is hampered and, at times, overwhelmed by a variety of non-strategic factors. For instance, powerful stakeholders such as unions, governments, and founding families may use their influence to push to satisfy competing demands, muddling firms' strategic intent. Other factors such as government regulations, mimetic isomorphism, management fads and fashions, industry traditions, cultural milieu (both within and outside the firm), and sociological imprinting may be determinants of firms' strategic practices in addition to strategic concerns.
}

This argument suggests that firms' management of pipelines could reflect non-rent-seeking criteria such as social justice, commitments to local communities, and long-term staffing concerns such as keeping managerial succession within entrepreneurial founding families. (We acknowledge that such concerns could have a strategic character to them at times.) Not surprisingly, these generally nonstrategic criteria have received relatively little attention from strategic human resource and human capital scholars because of a scholarly tendency to focus on small groups of elite workers such as investment analysts, lawyers, scientists, and athletes where the returns to strategic intent can be high relative to other types of workers (e.g., Rivera, 2015).

The more holistic portfolio approach addresses the internal needs for staffing as well as the demands of various stakeholders. To some degree, managing stakeholder desires may be strategic-that is, satisfying important stakeholders can be advantageous-and yet result in the establishment of pipelines that do not serve a strategic purpose for a firm's human capital resource. Consider how statefunded colleges and universities come under pressure to fill their halls with students from the state and often come under the direction of powerful constituents or even governmental representatives. Such pressures may mean developing pipelines solely for the purpose of satisfying the stakeholder despite their low financial return. Confronted with increased competition, the same school may also develop programs for out-of-state students or invest in pipelines to more fruitful areas in state. The portfolio, then, may have some intentional pipelines that appear nonstrategic for serving their intended purpose (i.e., accessing workers, or here students) but be strategic to the extent that they satisfy a major stakeholder (e.g., such as a major financial benefactor who desires a program to be developed in his or her home area, despite its inefficiency).

Pipelines emerge for a variety of other nonstrategic reasons. Managers are subject to limitations in their decision making, as various characteristics and motives affect their decisions in ways that may not always align with what a purely rational firm owner who is maximizing economic rents would desire (cf. Hambrick \& Mason, 1984; Jensen \& Meckling, 1976). As such, we theorize that firms' employment of pipelines in their portfolios will reflect some of these nonstrategic factors affecting managers' decisions and suggest a few particularly problematic ones.

\section{Institutional Pressures}

Though the needs of the organization and the characteristics of the labor market shift over time, managers may continue to use pipelines in response to institutional pressures rather than for their competitive value (Jorgensen et al., 2016). Consider how once pipelines are in place, it may be natural that managers use them simply out of unquestioned habit or routine. Pipelines may also form as a result of some pressure from institutional stakeholders. For example, institutional forces to increase diversity are prominent in many industrialized contexts. Internally, organizations often have diversity committees or departments that encourage firms to staff positions with more diverse candidates. These efforts can lead to better decision-making and group performance in dynamic contexts and thus be a special form of building competitive advantage 
(Roberge \& van Dick, 2010). In contrast, external institutional factors that tend to raise costs without such benefits, such as client mandates for a service from a more or less specific workforce (e.g., mandating unionized labor or sourcing from certain geographic regions), is nonstrategic from the standpoint of the firm in that the benefits to the firm may be questionable, or even negative when considered in totality, but yet benefit the external stakeholder (e.g., accumulating workforce power). Such forces that do not add value, or even detract from it, are coercive and tend to provide parity at best, if not disadvantage (DiMaggio \& Powell, 1983).

\section{Managerial Preferences and Agency}

Individualized interests of staffing managers may not always align perfectly with what is best for the firm (Jensen \& Meckling, 1976). When managers have the task of repeatedly staffing particular positions under their control, they may choose to staff with pipelines that are in their own best interests but not the firm's. For example, managers can choose to staff with a pipeline to an alma mater, a way of validating their own identities and others with that affiliation (Hogg \& Terry, 2000) or securing some other benefit (e.g., prestige, access) that does not benefit the firm. Or managers may choose to staff from a particular faction within the organization to gain political capital, despite the fact that another source might be in the better interest of the firm. These agentic forces can be powerful in the choice among pipelines.

Management preferences can also reflect managerial identities and values rather than a competitive calculus. Staffing managers have individual values, biases, and personalities that affect the decisions they make on behalf of their firms (Hambrick \& Mason, 1984). For example, managers more willing to accept risk may purposefully choose a narrower portfolio, while more risk-averse managers may desire a broader portfolio and the options it provides. Beyond risk preferences, other dispositional characteristics of managers may also affect the breadth of portfolios. Ultimately, there are many dispositional managerial factors that may affect their strategic choices in pipeline portfolios, pointing to the fact that portfolios emerge for both rational (i.e., guarding against risk) and nonrational (e.g., risk preference, agentic) reasons. Firms more able to avoid valuedestroying nonrationality in portfolio development likely capture more human capital value.

\section{Intentionality}

Managers operate with a degree of intentionality in selecting and culling strategic initiatives, but other evolutionary dynamics also play a role (Levinthal, 2017). Human capital resource heterogeneity could come about intentionally via pipelines, or, alternatively, pipelines that provide strategic value could materialize unintentionally (Barney, 1986). Consider how a firm may hire an employee from a labor source such as a university's social group, then that employee refers another from the same source and so on, unintentionally creating a pipeline. As more individuals from the same labor source are in the firm, there is an even higher likelihood of homophily and a shared desire to select from their common source. For another example, certain law firms are notorious for hiring only from a single law school-which started with hiring the first lawyer from that school and may have slowly built up because of routine and eventually become a pipeline. This phenomenon raises two related questions. To what degree are these pipelines intentionally cultivated or culled? And how does intentionality affect the firm's ability to create and capture pipeline value and to prevent value-destroying pipelines from emerging unintentionally? These questions are particularly intriguing as firms evolve and grow.

To recap, various strategic and nonstrategic factors affect managers' decisions for better or worse (Jorgensen et al., 2016). The different strategic and nonstrategic drivers of pipelines and portfolios provide another way to categorize pipeline types. Beyond differences in pipelines' scopes and imperfection matching, there is great variance in the reasons why pipelines emerge. Such differences in the motives of firm actors who initiate pipelines (i.e., to differentiate from competitors, to gain legitimacy from the firm, or in response to the whims of managers) doubtlessly affect the benefits that firms are able to derive from a pipeline or set of pipelines in a portfolio. Additionally, the differences in circumstances that create pipelines, absent the strategic intent of firm actors, also affect the types of pipelines that arise and their benefits. Addressing these drivers offers opportunities to better understand the performance implications of these staffing tools.

\section{New Future Staffing Arrangements}

It is reasonable to assume that firms prefer staffing from sources where they are most embedded and have the strongest pipelines, and such pipelines will 
likely constitute the most important parts of pipeline portfolios. Theoretically, this suggests that firms may engage in increasingly integrative strategies with their pipeline organizations to improve the rents from acquiring from particularly fruitful talent sources (Gardner, 2005). Should environmental conditions foster a heightened strategic priority for cultivating specific pipelines, firms may acquire source organizations completely and convert external hiring to internal pipelines, reducing threats of external contingencies (Pfeffer \& Salancik, 1978). This logic opens the possibility to currently unpracticed future staffing practices, such as universities and trade schools completely owned and integrated within firms. Current trends of firm skill gaps and failing universities suggest that such integration may be feasible in the near future (Cappelli, 2012; Cooper, 2016). Labor markets and their imperfections shift over time, providing inducements for firms to restructure their portfolios to match new realities. Unexpected new pipelines may consequently materialize. Thus, investgating the births and deaths of specific pipelines and understanding the processes of pipeline portfolio structuring are intriguing avenues of research.

\section{A More Holistic Staffing Perspective}

Our theory of pipeline staffing has the potential to democratize current research in firm staffing beyond stars and top managers, to understand a wider range of human capital sourcing phenomena that can have firm-level performance implications. Pipelines can provide an advantage to staff any position within any firm, from highly strategic contractors to workers with commoditized low-value contributions to stable professionals who protect the routinized administrative functions of the firm to the highcommitment and high-value long-term workforce (Lepak \& Snell, 1999; Tsui et al., 1995). Turnover and replacement rates may be higher for workers not compensated at market premiums for their services, so pipelines might be particularly relevant for nonelite workers. Yet pipelines may also develop for a host of other reasons, and the resulting pipeline portofolios have important implications for the firm, such as their return on pipeline investment, firm staffing practices, and ultimately performance.

Beyond the various research questions pipelines and portfolios pose, we expect that such differences will be visible empirically. This is not to say that measurement will be free of challenges; indeed, subsequent quantitative research will need to develop measures of various aspects such as breadth and strength of pipelines and portfolios and observe such differences across firms over time. Likewise, qualitative research could observe how and why pipelines and portfolios are managed as they are. While tried and true methods such as surveying and interviewing should be fruitful, advancements in research methodology, improved access to data on workers within firms, and technology that allows us to leverage data more completely than ever may serve to enable expanding research. Given the vast number of questions, we expect that researchers will be able to build a body of research that builds on our concept of pipelines and portfolios, advancing understanding of staffing in substantial ways.

\section{CONCLUSION}

Very little theory concerning pipelines and their portfolios has existed up to this point. This void is problematic because it means received understanding of human capital acquisition and its relationship with firm performance is at best incomplete. Accordingly, we highlighted pipeline ramifications for HR and human capital scholars, examining strategic factor markets, interfirm competition, competitive advantage, and corporate social responsibility (e.g., social justice and inclusive workforces). Social scientists who examine pipelinelike phenomena outside the management realm can also leverage the typology and frameworks presented in this paper to advance theory and research in their respective fields (cf. Whetten, Felin, \& King, 2009).

Thought leaders who grapple with talent issues for particular industries or occupations also have had little middle-range theory on pipelines to guide them (cf. Merton, 1968). Introducing a shared conceptual framework and typology of pipelines has the potential to transform thinking about some of the most complex challenges facing firms (workforce inclusion, succession planning), occupations, and industries (underemployment, skill gaps). Thus, a wide audience can benefit from this perspective (e.g., research on the supply of dentists; Hryhorczuk et al., 2008).

Pipelines attract scholarly and popular press attention because they have intuitive and noteworthy implications for firm resource positions, employee mobility, individuals' career outcomes, and economic rents derived from human capital. Our paper serves as a guidepost for future pipeline scholarship and captures a timely opportunity to ground human 
capital research in relevant and theoretically rigorous ways (Kryscynski \& Ulrich, 2015).

\section{REFERENCES}

AAGE. (2015). Pipelines and pathways: Emerging talent. Australian Association of Graduate Employers, 27th Annual AAGE Graduate Recruitment and Development Conference, Sydney.

Acosta, D., \& Olsen, P. (2006). Meeting the needs of regional minority groups: The University of Washington's programs to increase the American Indian and Alaskan native physician workforce. Academic Medicine, 81, 863-870.

Alexander, C. J., \& Mitchell, D. A. (2010). The role of enrichment programs in strengthening the academic pipeline to dental education. Journal of Dental Education, 74, S110-S120.

Arthur, M. B., \& Rousseau, D. M. (2001). The boundaryless career: A new employment principle for a new organizational era. New York: Oxford University Press.

Ashforth, B. E., Kreiner, G. E., Clark, M. A., \& Fugate, M. (2007). Normalizing dirty work: Managerial tactics for countering occupational taint. Academy of Management Journal, 50(1), 149-174.

Atchison, K. A., et al. (2011). Comparison of extramural clinical rotation days: Did the pipeline program make a difference? Journal of Dental Education, 75, 52-61.

Barley, S. R. (1989). Careers, identities, and institutions: The legacy of the Chicago School of Sociology. In M. B. Arthur, D. T. Hall, \& B. S. Lawrence (Eds.), Handbook of career theory (pp. 41-65). New York: Oxford University Press.

Barney, J. B. (1986). Strategic factor markets: Expectations, luck, and business strategy. Management Science, 32, 1230-1241.

Barney, J. B. (1991). Firm resources and sustained competitive advantage. Journal of Management, 17(1), 99-120.

Barney, J. B., \& Wright, P. M. (1998). On becoming a strategic partner: The role of human resources in gaining competitive advantage. Human Resource Management, 37(1), 31-46.

Beeson, J., \& Valerio, A. M. (2012). The executive leadership imperative: A new perspective on how companies and executives can accelerate the development of women leaders. Business Horizons, 55, 417-425.

Bersin, J. (2012, July 30). It's not the CEO, it's the leadership strategy that matters. Forbes Magazine. Retrieved from https://www.forbes.com/sites/joshbersin/2012/ 07/30/its-not-the-ceo-its-the-leadership-strategy-thatmatters/\#59a21e9f6db8
Bersin, J. (2016, October 6). The five elements of a strong leadership pipeline. Harvard Business Review. Retrieved October 14, 2016, from https://hbr.org/2016/ 10/the-5-elements-of-a-strong-leadership-pipeline

Bidwell, M. (2011). Paying more to get less: The effects of external hiring versus internal mobility. Administrative Science Quarterly, 56(3), 369-407.

Bidwell, M. J. (2013). What happened to long-term employment? The role of worker power and environmental turbulence in explaining declines in worker tenure. Organization Science, 24(4), 1061-1082.

Bidwell, M., \& Briscoe, F. (2010). The dynamics of interorganizational careers. Organization Science, 21(5), 1034-1053.

Bidwell, M., Briscoe, F., Fernandez-Mateo, I., \& Sterling, A. (2013). The employment relationship and inequality: How and why changes in employment practices are reshaping rewards in organizations. Academy of Management Annals, 7, 61-121.

Bidwell, M., \& Keller, J. R. (2014). Within or without? How firms combine internal and external labor markets to fill jobs. Academy of Management Journal, 58(4), 1035-1055.

Bidwell, M., Won, S., Barbulescu, R., \& Mollick, E. (2015). I used to work at Goldman Sachs! How firms benefit from organizational status in the market for human capital. Strategic Management Journal, 36(8), 1164-1173.

Bonet, R., Cappelli, P., \& Hamori, M. (2013). Labor market intermediaries and the new paradigm for human resources. Academy of Management Annals, 7, 341-392.

Brands, R. A., \& Fernandez-Mateo, I. (2017). Leaning out: How negative recruitment experiences shape women's decisions to compete for executive roles. Administrative Science Quarterly, 62, 405-442.

Breaugh, J. A. (2008). Employee recruitment: Current knowledge and important areas for future research. Human Resource Management Review, 18(3), 103118.

Brymer, R. A. (2016, June 20). What new hiring methods say about Wall Street's diversity problem. Fortune. Retrieved October 14, 2016, from http://fortune.com/ 2016/06/20/ wall-street-new-hiring-diversity/

Brymer, R. A., Molloy, J. C., \& Gilbert, B. A. (2014). Human capital pipelines: Competitive implications of repeated interorganizational hiring. Journal of Management, 40, 483-508.

Brymer, R. A., \& Sirmon, D. G. (2018). Pre-exit bundling, turnover of professionals, and firm performance. Journal of Management Studies, 55(1), 146-173.

Campbell, B. A., Coff, R., \& Kryscynski, D. (2012). Rethinking sustained competitive advantage from 
human capital. Academy of Management Review, 37(3), 376-395.

Campbell, B. A., Kryscynski, D., \& Olson, D. M. (2017). Bridging strategic human capital and employee entrepreneurship research: A labor market frictions approach. Strategic Entrepreneurship Journal, 11(3), 344-356.

Campbell, B. A., Saxton, B. M., \& Banerjee, P. M. (2014). Resetting the shot clock: The effect of co-mobility on human capital. Journal of Management, 40, 531-556.

Campion, M. C., Ployhart, R. E., \& Campion, M. A. (2017). Using recruitment source timing and diagnosticity to enhance applicants' occupation-specific human capital. Journal of Applied Psychology, 102(5), 764781.

Cappelli, P. (2008a). Talent management for the twentyfirst century. Harvard Business Review, 86, 74-96.

Cappelli, P. (2008b). Talent on demand. Boston: Harvard Business Press.

Cappelli, P. (2012). Why good people can't get jobs: The skills gap and what companies can do about it. Philadelphia: Wharton Digital Press.

Cappelli, P., \& Hamori, M. (2014). Understanding executive job search. Organization Science, 25, 1511-1529.

Carnahan, S., \& Somaya, D. (2015). The other talent war: Competing through alumni. MIT Sloan Management Review, 56(3), 14-16.

Carson, D. B., Schoo, A., \& Berggren, P. (2015). The "rural pipeline" and retention of rural health professionals in Europe's northern peripheries. Health Policy (Amsterdam), 119, 1550-1556.

Center for Audit Quality. (2017). Discover audit. Retrieved December 8, 2017, from http://www.thecaq.org/ discover-audit

Chadwick, C. (2017). Toward a more comprehensive model of firms' human capital rents. Academy of Management Review, 42(3), 499-519.

Charan, R., Drotter, S., \& Noel, J. (2010). The leadership pipeline: How to build the leadership powered company. Hoboken, NJ: John Wiley \& Sons.

Clewell, B. C., \& Villegas, A. M. (1999). Creating a nontraditional pipeline for urban teachers: The pathways to teaching careers model. Journal of Negro Education, $68,306-317$.

Cobb, A. (2016). How firms shape income inequality: Stakeholder power, executive decision-making, and the structuring of employment relationships. Academy of Management Review, 41, 324-348.

Coff, R. W. (1997). Human assets and management dilemmas: Coping with hazards on the road to resourcebased theory. Academy of Management Review, 22(2), 374-402.
Coleman, J. S. (1988). Social capital in the creation of human capital. American Journal of Sociology, 94, S95-S120.

Collins, C. J., \& Han, J. (2004). Exploring applicant pool quantity and quality: The effects of early recruitment practice strategies, corporate advertising, and firm reputation. Personnel Psychology, 57(3), 685-717.

Conger, J. A., \& Fulmer, R. M. (2003). Developing your leadership pipeline. Harvard Business Review, 82, 76-84.

Connolly, A., \& Phillips-Connolly, K. (2010). Building a talent pipeline: Development of the "Alltech MiniMBA." International Food and Agribusiness Management Review, 13, 153-161.

Cooper, P. (2016, September 12). Why universities are failing. Atlanta, GA: Foundation for Economic Education. Retrieved May 27, 2017, from https:/fee.org/ articles/why-universities-are-failing/

Cragen, O., Nyberg, A., \& Wright, P. (2016). CEO succession: What we know and where to go? Journal of Organizational Effectiveness: People and Performance, 3(3), 222-264.

Dierickx, I., \& Cool, K. (1989). Asset stock accumulation and sustainability of competitive advantage. Management Science, 35(12), 1504-1511.

DiMaggio, P. J., \& Powell, W. W. (1983). The iron cage revisited: Institutional isomorphism and collective rationality in organizational fields. American Sociological Review, 48(2), 147-160.

Dobrev, S. D. (2005). Career mobility and job flocking. Social Science Research, 34(4), 800-820.

Dutta-Moscato, J., Gopalakrishnan, V., Lotze, M. T., \& Becich, M. J. (2014). Creating a pipeline of talent for informatics: STEM initiative for high school students in computer science, biology, and biomedical informatics. Journal of Pathology Informatics, 5, 12-21.

Eckardt, R., Skaggs, B., \& Lepak, D. (2018). An examination of the firm-level performance impact of cluster hiring in knowledge-intensive firms. Academy of Management Journal, 61(3), 919-944.

Ernst \& Young. (2017). Shaping the future workforce through education. Retrieved December 8, 2017, from http://www.ey.com/us/en/about-us/corporateresponsibility/ey-supporting-education

Evans, T. (2010, May 2). On master agreements: Connecting firms with university research and graduates. Wall Street Journal.

Fernandez-Mateo, I., \& Fernandez, R. (2016). Bending the pipeline? Executive search and gender inequality in top management jobs. Management Science, 62, 3636-3655. 
Fischer, K. (2013). The employment mismatch. Chronicle of Higher Education, 43, 23-24.

Formicola, A., et al. (2009). The dental pipeline program's impact on access disparities and student diversity. Journal of the American Dental Association, 140, 346353.

Garbuio, M., King, A. W., \& Lovallo, D. (2011). Looking inside psychological influences on structuring a firm's portfolio of resources. Journal of Management, 37(5), 1444-1463.

Gardner, T. M. (2005). Human resource alliances as a means of improving the recruiting, management, and retention of employees. International Journal of $\mathrm{Hu}$ man Resource Management, 16(6), 1057-1074.

Gellman, L. (2015, April 1). How 300 emails led to a summer internship on Wall Street. Wall Street Journal. Retrieved May 27, 2017, from https://www.wsj.com/ articles/how-300-emails-led-to-a-summer-job-on-wallstreet-1427932335

Hambrick, D. C., \& Mason, P. A. (1984). Upper echelons: The organization as a reflection of its top managers. Academy of Management Review, 9(2), 193-206.

Hamori, M., Bonet, R., \& Cappelli, P. (2011). How organizations obtain the human capital they need. In A. Burton-Jones \& J.-C. Spender (Eds.), The Oxford handbook of human capital (pp. 309-332). Oxford, UK: Oxford University Press.

Hatch, N. W., \& Dyer, J. H. (2004). Human capital and learning as a source of sustainable competitive advantage. Strategic Management Journal, 25(12), 11551178.

Helfat, C. E., Harris, D., \& Wolfson, P. J. (2006). The pipeline to the top: Women and men in the top executive ranks of U.S. corporations. Academy of Management Perspectives, 20, 42-64.

Ho, K. (2009). Liquidated: An ethnography of Wall Street. Durham, NC: Duke University Press.

Hogg, M. A., \& Terry, D. J. (2000). Social identity and selfcategorization processes in organizational contexts. Academy of Management Review, 25(1), 121-140.

Hryhorczuk, C., et al. (2008). A model for selection and assessment of community-based sites for dental students' extramural clinical experiences. Journal of Dental Education, 72, 153-171.

Ibarra, H., Carter, N. M., \& Silva, C. (2010). Why men still get more promotions than women. Harvard Business Review, 88(9), 80-85.

Jensen, M. C., \& Meckling, W. H. (1976). Theory of the firm: Managerial behavior, agency costs and ownership structure. Journal of Financial Economics, 3(4), 305-360.
Jorgensen, F., Chadwick, C., \& Antonacopoulou, E. (2016). Qualitative insights on the evolution of firms' strategic human capital management practices (Working Paper). Lawrence, KS: University of Kansas.

Karpinski, C. F. (2006). Bearing the burden of desegregation: Black principals and brown. Urban Education, 41, 237-276.

Kerr, C. (1977). Labor markets and wage determination: The balkanization of labor markets and other essays. Berkeley, CA: University of California Press.

Kristof-Brown, A. L., Zimmerman, R. D., \& Johnson, E. C. (2005). Consequences of individuals' fit at work: A meta-analysis of person-job, person-organization, and person-supervisor fit. Personnel Psychology, 58(2), 281-342.

Kryscynski, D., \& Ulrich, D. (2015). Making strategic human capital relevant: A time-sensitive opportunity. Academy of Management Perspectives, 29(3), 357-369.

Lehmberg, D., Rowe, W., White, R., \& Phillips, J. (2009). The GE paradox: Competitive advantage through fungible non-firm specific investment. Journal of Management, 35, 1129-1153.

Lepak, D. P., \& Snell, S. A. (1999). The human resource architecture: Toward a theory of human capital allocation and development. Academy of Management Review, 24(1), 31-48.

Levinthal, D. A. (2017). Mendel in the C-suite: Design and evolution of strategies. Strategy Science, 2(4), 282-287.

Mahoney, J. T., \& Qian, L. (2013). Market frictions as building blocks of an organizational economics approach to strategic management. Strategic Management Journal, 34(9), 1019-1041.

Maritan, C., \& Peteraf, M. (2011). Building a bridge between resource acquisition and resource accumulation. Journal of Management, 37, 1374-1389.

Marx, M., \& Timmermans, B. (2018). Hiring molecules, not atoms: Comobility and wages. Organization Science, 28(6), 1115-1133.

Mawdsley, J. K., \& Somaya, D. (2016). Employee mobility and organizational outcomes: An integrative conceptual framework and research agenda. Journal of Management, 42(1), 85-113.

Maxwell, M. (2004). Recruitment realities: Building an HR/nursing partnership. Nursing Economics, 22, 86-87.

McGee, R, Jr., Saran, S., \& Krulwich, T. A. (2012). Diversity in the biomedical research workforce: Developing talent. Mount Sinai Journal of Medicine: A Journal of Translational and Personalized Medicine, 79(3), 397-411.

McGrath, R. G., Ferrier, W. J., \& Mendelow, A. L. (2004). Real options as engines of choice and heterogeneity. Academy of Management Review, 29(1), 86-101. 
McKinley, W. (2007). Managing knowledge in organization studies through instrumentation. Organization, 14(1), 123-146.

Merton, R. (1968). Social theory and social structure. New York: Free Press.

Miles, M. B., \& Huberman, A. M. (1994). Qualitative data analysis: An expanded sourcebook. Thousand Oaks, CA: Sage.

Monroe, K. R., \& Chiu, W. F. (2010). Gender equality in the academy: The pipeline problem. PS: Political Science \& Politics, 43(2), 303-308.

Myung, J., Loeb, S., \& Horng, E. (2011). Tapping the principal pipeline: Identifying talent for future school leadership in the absence of formal succession-management programs. Educational Administration Quarterly, 47(5), 695-727.

National Association of Black Accountants. (2017). Accounting career awareness program. Retrieved December 8, 2017, from http://www.nabainc.org/acap

Osterman, P. (2011). The promise, performance and policies of community colleges. In B. Wildavsky, A. P. Kelly, \& K. Carey (Eds.), Reinventing higher education: The promise of innovation (pp. 129-158). Cambridge, MA: Harvard Education Press.

Osterman, P., \& Burton, M. D. (2006). Ports and ladders: The nature and relevance of internal labor markets in a changing world. In S. Ackroyd, R. Batt, P. Thompson, \& P. S. Tolbert (Eds.), The Oxford handbook of work and organization (pp. 425-448). New York: Oxford University Press.

Osterman, P., Kochan, T. A., Locke, R. M., \& Piore, M. J. (2002). Working in America: Blueprint for a new labor market. Cambridge, MA: MIT Press.

Oxley, J. E., Rivkin, J. W., \& Ryall, M. D. (2010). The Strategy Research Initiative: Recognizing and encouraging high-quality research in strategy. Strategic Organization, 8(4), 377-386.

Pell, A. N. (1996). Fixing the leaky pipeline: Women scientists in academia. Journal of Animal Science, 74(11), 2843-2848.

Peteraf, M. A. (1993). The cornerstones of competitive advantage: A resource-based view. Strategic Management Journal, 14(3), 179-191.

Pfeffer, J., \& Salancik, G. R. (1978). The external control of organizations: A resource dependence perspective. Palo Alto, CA: Stanford University Press.

Phillips, J. M., \& Gully, S. M. (2015). Multilevel and strategic recruiting: Where have we been, where can we go from here? Journal of Management, 41(5), 1416-1445.

Ployhart, R. E. (2006). Staffing in the 21st century: New challenges and strategic opportunities. Journal of Management, 32(6), 868-897.
Ployhart, R. E., \& Cragun, O. R. (2017). Human capital resource complementarities. In D. Collings, K. Mellahi, \& W. F. Cascio (Eds.), The Oxford handbook of talent management (Ch. 7). New York: Oxford University Press.

Ployhart, R. E., \& Moliterno, T. P. (2011). Emergence of the human capital resource: A multilevel model. Academy of Management Review, 36(1), 127-150.

Ployhart, R. E., Nyberg, A. J., Reilly, G., \& Maltarich, M. A. (2014). Human capital is dead. Long live human capital resources! Journal of Management, 40, 371-398.

Ployhart, R. E., Schneider, B., \& Schmitt, N. (2006). Staffing organizations: Contemporary practice and research. Mahwah, NJ: Lawrence Erlbaum Associates.

Podsakoff, N. P., LePine, J. A., \& LePine, M. A. (2007). Differential challenge stressor-hindrance stressor relationships with job attitudes, turnover intentions, turnover, and withdrawal behavior: A meta-analysis. Journal of Applied Psychology, 92(2), 438-454.

Porter, M. E. (1980). Competitive strategy: Techniques for analyzing industries and competition. New York: Free Press.

Rackley, B. P., Wheat, J. R., Moore, C. E., Garner, R. G., \& Harrell, B. W. (2003). The Southern Rural Access Program and Alabama's Rural Health Leaders Pipeline: A partnership to develop needed minority health care professionals. Journal of Rural Health, 19, 354-360.

Ready, D. A., \& Conger, J. A. (2007). Make your company a talent factory. Harvard Business Review, 85(6), 68-77.

Rivera, L. A. (2015). Pedigree: How elite students get elite jobs. Princeton, NJ: Princeton University Press.

Roberge, M. E., \& van Dick, R. (2010). Recognizing the benefits of diversity: When and how does diversity increase group performance? Human Resource Management Review, 20(4), 295-308.

Rocha, V., Carneiro, A., \& Varum, C. (2018). Leaving employment to entrepreneurship: The value of coworker mobility in pushed and pulled-driven startups. Journal of Management Studies, 55(1), 60-85.

Roth, A. E. (2007). The art of designing markets. Harvard Business Review, 85(10), 118-126.

Ryan, A. M., \& Ployhart, R. E. (2014). A century of selection. Annual Review of Psychology, 65, 693-717.

Schneider, B. (1987). The people make the place. Personnel Psychology, 40(3), 437-453.

Sikora, D. M., \& Ferris, G. R. (2014). Strategic human resource practice implementation: The critical role of line management. Human Resource Management Review, 24(3), 271-281.

Sirmon, D. G., Hitt, M. A., \& Ireland, R. D. (2007). Managing firm resources in dynamic environments to create 
value: Looking inside the black box. Academy of Management Review, 32(1), 273-292.

Somaya, D., Williamson, I. O., \& Lorinkova, N. (2008). Gone but not lost: The different performance impacts of employee mobility between cooperators versus competitors. Academy of Management Journal, 51, 936-953.

Spender, J. C. (1989). Industry recipes. Oxford, UK: Basil Blackwell.

Stewart, M. M., Williamson, I. O., \& King, J. E. (2008). Who wants to be a business $\mathrm{PhD}$ ? Exploring minority entry into the faculty "pipeline." Academy of Management Learning \& Education, 7, 42-55.

Stigler, G. J. (1957). Perfect competition, historically contemplated. Journal of Political Economy, 65(1), 1-17.

Suddaby, R. (2010). Editor's comments: Construct clarity in theories of management and organization. Academy of Management Review, 35(3), 346-357.

Titzer, J. L., Shirey, M. R., \& Hauck, S. (2014). A nurse manager succession-planning model with associated empirical outcomes. Journal of Nursing Administration, 44, 37-46.

Tsui, A. S., Pearce, J. L., Porter, L. W., \& Hite, J. P. (1995). Choice of employee-organization relationship: Influence of external and internal organizational factors. Research in Personnel and Human Resources Management, 13, 117-151.

Ulrich, D., \& Smallwood, N. (2007). Building a leadership brand. Harvard Business Review, 85, 92-100.

U.S. Department of Education. (2016). Science, technology, engineering, and math: Education for global leadership. Retrieved October 6, 2016, from www.ed.gov/stem

Wernerfelt, B. (2011). Invited editorial: The use of resources in resource acquisition. Journal of Management, 37, 1369-1373.

Whetten, D. A., Felin, T., \& King, B. G. (2009). The practice of theory borrowing in organizational studies: Current issues and future directions. Journal of Management, $35,537-563$.

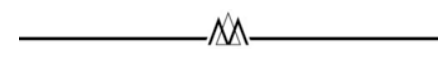

Rhett A. Brymer (rhett.brymer@uc.edu) is an assistant professor of management at the University of Cincinnati's Carl H. Lindner College of Business. He received his Ph.D. from Texas A\&M University. His research interests include how firms source talent and the firm implications of hiring, turnover, and mobility.

Clint Chadwick (clint.chadwick@ku.edu) is a professor of strategy and human resource management at the University of Kansas. He received his Ph.D. in management from The Wharton School. His research interests include the impact of human resource systems and human capital on firm competitiveness, the strategic roles of HRM departments, and downsizing and strategic renewal in organizations.

Aaron D. Hill (aaron.hill@warrington.ufl.edu) is on the faculty of the Warrington College of Business at the University of Florida. His research interests include the personal characteristics, compensation, and job mobility of executives. He received his Ph.D. from Oklahoma State University.

Janice C. Molloy (janicecmolloy@gmail.com) is an associate professor of management studies at the University of Michigan in Dearborn. She studies human capital from labor market and strategic management perspectives. Her research has been published in Strategic Management Journal, Journal of Management, and Academy of Management Review.

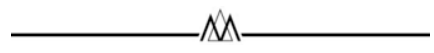

APPENDIX

\section{Pipeline Concept Review Process}

We used best practices, such as multiple coders and a systematic search of the scholarly literature, to conduct the systematic review (e.g., Miles \& Huberman, 1994), and sought pipeline scholarship within and outside the management field. Our sampling frames were the top 30 management journals based on the 2014 Web of Science five-year impact factors and a wider search of Web of Science across all disciplines. For a broad understanding of pipeline scholarship, we reviewed articles published between 1995 and 2016.

To identify articles to include in our sample, we searched the management journals for the word pipeline occurring anywhere within an article. The broader Web of Science search logic resulted in articles far beyond our scope (e.g., petroleum pipelines, pipeline construction, drug pipelines, etc.), so we narrowed our search to articles using the term pipeline paired with talent, recruiting, hiring, or human capital anywhere within the article. These searches yielded 269 unique articles. We understood that this search logic would lead to some articles that did not pertain to human capital but continued with this approach to ensure a comprehensive review. To identify the final sample, two authors individually read each article and agreed on which articles pertained to human capital pipelines specifically. Articles culled from the sample include manuscripts on physical, sales, drug development, and other pipelines unrelated to talent management. The final sample contained 107 articles.

We examined the articles for the pipeline concept and independently coded information about each article. Two authors discussed the types of information appropriate to code based on features of the concept we 
could ascertain. We created columns with features consistently searched for in each article, including the field of publication (e.g., medical sciences, management, education), year of publication, the pipeline's sponsor (e.g., professional association, specific firm facing talent shortage), the purpose of the pipeline (e.g., increasing diversity), who moves through the pipeline (e.g., undergraduate students, midlevel managers), and the entities the pipeline connects (e.g., a university and hiring firm). Each article was coded, and the authors discussed the few discrepancies to arrive at a final coding resulting in full agreement. To complement the journal sample, we also examined scholarly books (e.g., Cappelli, 2008b; Charan et al., 2010; Rivera, 2015) and the popular press pertaining to pipelines.

\section{Highlights}

Most $(80.4 \%, n=86)$ of the 107 pipeline articles were published outside of the management field. The literatures with the most human capital pipeline scholarship were the medical sciences $(35.5 \%, n=$ 38 ), applied physical sciences $(28.0 \%, n=30)$, and management $(19.6 \%, n=21)$, along with a host of other social sciences $(16.8 \%, n=18)$.

Scholarship invoking the term pipeline has swelled recently. Publication of $95.3 \%$ of the sample has been in the past decade. Additionally, there has been a recent surge in practice, popular press, and scholarly books describing pipelines as a common staffing approach (e.g., AAGE, 2015; Bersin, 2016; Brymer, 2016; Evans, 2010). 
Copyright of Academy of Management Perspectives is the property of Academy of Management and its content may not be copied or emailed to multiple sites or posted to a listserv without the copyright holder's express written permission. However, users may print, download, or email articles for individual use. 